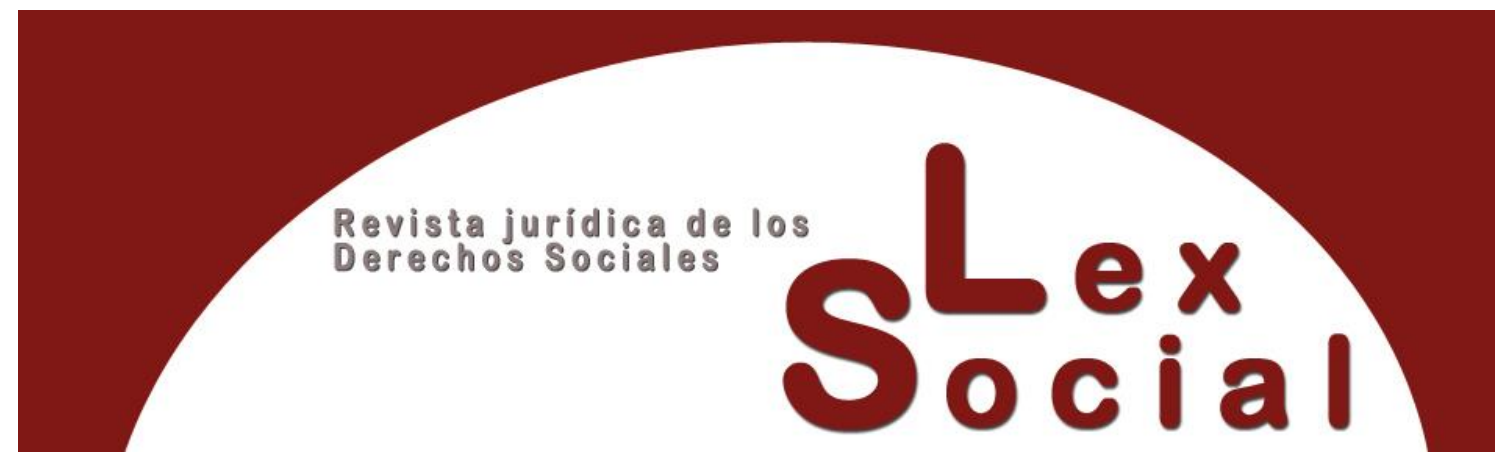

\title{
LA PREVENCIÓN DE RIESGOS EN EL TRABAJO DOMÉSTICO Y DE CUIDADOS EN ESPAÑA: LA NECESIDAD DE RATIFICAR LOS CONVENIOS 189 Y 190 DE LA OIT ${ }^{1}$
}

\section{THE PREVENTION OF OCCUPATIONAL RISKS TO DOMESTIC WORKERS AND HOME CARERS IN SPAIN: THE NEED TO RATIFY ILO CONVENTIONS 189 AND 190}

PILAR FERNÁNDEZ ARTIACH Profesora Titular de Derecho del Trabajo y de la Seguridad Social Universitat de València http://orcid.org/0000-0003-4025-1691

ELENA GARCÍA TESTAL Profesora Titular de Derecho del Trabajo y de la Seguridad Social

Universitat de València https://orcid.org/0000-0003-3069-0631

\begin{abstract}
Cómo citar este trabajo: Fernández Artiach, P. y García Testal, E. La prevención de riesgos en el trabajo doméstico y de cuidados en España: la necesidad de ratificar los Convenios 189 y 190 de la OIT (2021). Lex Social, Revista De Derechos Sociales, 11 (2), 628-661. https://doi.org/10.46661/lexsocial.5964
\end{abstract}

\section{RESUMEN}

La prevención de los riesgos laborales y de la violencia y acoso en el trabajo es una más de las asignaturas pendientes en el tratamiento y protección del trabajo doméstico y de cuidados en España. Las escasas referencias normativas, así como

\footnotetext{
${ }^{1}$ Realizado en el marco de los I+D+I "Retos investigación" 2018 sobre Análisis jurídico y sociológico de las brechas de género en las transiciones trabajo-jubilación-trabajo: factores de la desigualdad y propuestas normativas", Ministerio de Ciencia e Innovación - Agencia Estatal de Investigación, ref. RTI2018-095888B-I00D; y del I+D de Generación del Conocimiento sobre Violencia, Trabajo y Género (VITRAGE), Ref. PGC2018-094912-B-I00, del Programa Estatal de Generación de Conocimiento y fortalecimiento científico y tecnológico del sistema de I+D+i del Ministerio de Ciencia, Innovación e Universidades.
} 
la ausencia de una decidida política preventiva en este sector, contrastan con las previsiones de dos Convenios de la OIT: el Convenio 189, sobre el trabajo decente para las trabajadoras y los trabajadores domésticos, del año 2011, y el Convenio 190, sobre la violencia y el acoso, de 2019, por lo que la anunciada ratificación de ambos exige una mirada crítica y un cambio hacia una auténtica perspectiva preventiva de los riesgos laborales de las trabajadoras domésticas en el contexto de trabajo decente.

Palabras Clave: riesgos laborales, trabajo doméstico, acoso laboral, violencia en el trabajo, OIT.

\begin{abstract}
One of the pending subjects in the treatment and protection of domestic and care work in Spain is the prevention of occupational risks and of violence and harassment at work. The few normative references, as well as the absence of a decided preventive policy in this sector, contrast with the provisions of two ILO Conventions: Convention 189, on decent work for domestic workers, from 2011, and Convention 190, on violence and harassment, of 2019, for which their announced ratification requires a critical look and a change towards an authentic preventive perspective of the occupational risks of domestic workers in the context of decent work.
\end{abstract}

KEYWORDS: occupational risks, domestic work, harassment at work, violence at work, ILO.

SUMARIO

I. Sobre la prevención de riesgos laborales y el trabajo doméstico y de cuidados

1. Las carencias del sistema normativo español en materia de seguridad y salud del trabajo doméstico

2. Dos elementos adicionales: la falta de sindicación y dificultades de control

3. Riesgos laborales y trabajo doméstico

4. Convenios OIT, ODS y trabajo decente

II. Salud, trabajo doméstico y Convenio 189-OIT

1. La protección de la salud en el Convenio 189-OIT y la Recomendación 201

2. La inexistente adaptación del ordenamiento español al contenido del Convenio 189 OIT y la Recomendación 201 en materia de protección de la salud 


\title{
III. Acoso y violencia en el trabajo doméstico y Convenio 190-OIT
}

1. El acoso y la violencia en el trabajo como riesgo para la salud en el Convenio 190OIT

2. El trabajo doméstico en el Convenio 190-OIT

\author{
IV. Reflexión final
}

Bibliografía

Anexo

\section{Sobre la prevención de riesgos laborales y el trabajo doméstico y de cuidados}

Abordamos en este trabajo la necesidad de cuestionar críticamente la falta de tratamiento en la normativa interna española de la prevención de riesgos laborales en general, y del acoso y la violencia en el trabajo en particular, en el trabajo doméstico y de cuidados ${ }^{2}$, entendiendo por éstos la realización de las tareas del hogar y de cuidados de personas en el hogar, a cambio de una retribución, y en el marco de una relación laboral de carácter especial regulada en el RD 1620/2011, de 14 de noviembre ${ }^{3}$.

\footnotetext{
${ }^{2}$ Sobre el trabajo de cuidados (remunerado y no remunerado), y la desigualdad por razón de género que supone, puede consultarse el informe de la OIT disponible en https://www.ilo.org/wcmsp5/groups/public/--dgreports/---dcomm/---publ/documents/publication/wcms_633168.pdf

${ }^{3}$ Aunque el contrato de trabajo ha sido el eje a partir del cual se han elaborado las normas laborales, pronto se desarrollaron modelos paralelos o regulaciones diferenciadas del prototipo, bajo la denominación de contratos especiales de trabajo o de relaciones laborales especiales (CARDENAL CARRO, Miguel, CARDENAL CARRO, Miguel, "A los 15 años de existencia de las relaciones laborales especiales. Un balance y una propuesta", Aranzadi Social, núm. 9 y 10, 2000). Así ocurrió en España, desde la Ley de Relaciones Laborales de 8 de abril de 1976 que se refirió a las relaciones laborales especiales, y que posteriormente fueron desarrolladas bajo la vigencia de la Ley 8/1980, de 10 de marzo, que aprobó el Estatuto de los Trabajadores. Este modelo tiene consecuencias importantes en el régimen jurídico de prestaciones de servicios, cada una de ellas cuenta con su propio sistema de fuentes, su propio régimen de contratación y de extinción de la relación, lo que no ha obstado para que estas diferencias hayan sido avaladas por el Tribunal Constitucional (STC 49/1983 y STC 26/1984). Además, su inclusión en el ámbito de protección del ordenamiento laboral se produce a través de su consideración como relación laboral especial, que ha supuesto el mantenimiento de un nivel de infraprotección en comparación con la relación laboral común (GARCIA TESTAL, Elena, "La extinción del contrato de trabajo de los trabajadores doméstico en España: un régimen jurídico injustificadamente diferenciado", Lex Social Revista de Derechos Sociales, Vol. 9, núm. 2/2019, p. 277). Sobre la relación especial puede verse, por todos, CORDERO GORDILLO, Vanesa, La relación laboral especial del servicio del hogar familiar, RD 1620/2011, de 14 de noviembre, Tirant lo Blanch, Valencia, 2014; y SALCEDO BELTRÁN, Carmen, "El trabajo doméstico en España: planteamientos y desafíos insoslayables frente a la "esclavitud moderna"”, Revista General de Derecho del Trabajo y de la Seguridad Social, núm. 55/2020. Debe añadirse que su modelo de protección social también ha venido siendo cuestionado críticamente, pues, pese a que la Ley 27/2011, de 1 de agosto, sobre actualización, adecuación y modernización del sistema de Seguridad Social dispuso la integración del Régimen Especial de la Seguridad Social de los Empleados de Hogar en el Régimen General, lo hizo mediante el establecimiento de un sistema especial, por lo que se mantiene la exclusión de determinadas protecciones, como la contingencia de desempleo: GARCIA TESTAL, Elena, "La necesidad de una protección por desempleo para los trabajadores domésticos en España", en Revista
} 
Concretamente, acudimos a los conceptos utilizados por la OIT para concretar el significado de la expresión trabajo doméstico, que designa el trabajo realizado en un hogar u hogares o para los mismos, y de cuya delimitación se derivan algunas inclusiones específicas a las que queremos hacer especial mención por su posible repercusión sobre la salud laboral. Así, desde la perspectiva del tiempo dedicado a la prestación de servicios, esta delimitación del trabajo doméstico incluye tanto a los trabajadores domésticos internos -cuyo lugar de residencia y de trabajo coincide-, como a las personas trabajadoras que prestan servicios para varios hogares en paralelo a tiempo parcial, circunstancia altamente frecuente en estas prestaciones de servicios; desde el punto de vista de los trabajos realizados queda incluido el conjunto de actividades y servicios domésticos que contribuyen al funcionamiento cotidiano del hogar y al bienestar y desarrollo de sus miembros, y que se refieren tanto al trabajo dentro del hogar como al que se realiza fuera de éste -labores de jardinería, conducción de vehículos, realización de compras y supervisión de los miembros de la familia- ${ }^{4}$. De manera que lo que define el trabajo doméstico es más el lugar en que se realiza y no estrictamente el tipo de tareas desempeñadas $^{5}$, pues las mismas funciones -limpieza, cuidados, compra y cocina de alimentos, cuidado de niños y personas mayores o dependientes, lavado y plancha de la ropa...- se realizan también en empresas y centros de trabajo en relación de dependencia y subordinación respecto de un empresario, y, sin embargo, el hecho significativo de realizarse en un hogar familiar tiene repercusiones incluso en lo que respecta a la ausencia de protección en materia de salud laboral.

En nuestra opinión resulta imprescindible recordar la infravaloración que, tradicional e históricamente, ha acompañado este tipo de labores, tanto desde el punto de vista económico -no genera beneficios económicos directos para los hogares, no se considera actividad económica, no computa en las estadísticas, ni en las estimaciones del PIB, ni en la formulación de políticas públicas-, como desde otras perspectivas como la inexistencia de una demanda de habilidades y cualificación específica ${ }^{6}$.

Igualmente consideramos preciso destacar los elementos principales del perfil de las personas que trabajan en el ámbito doméstico en España ${ }^{7}$, para entender a quiénes afecta

de Derecho Social, núm. 79, 2017, pp. 93-112; y de la misma autora, “Trabajo doméstico y COVID-19” en Actualidad Jurídica Iberoamericana, núm. 12 bis, mayo 2020, pp. 712-723.

${ }^{4}$ OELZ, Martin, "El Convenio y la Recomendación de la OIT sobre las trabajadoras y los trabajadores domésticos. Una oportunidad para la justicia social”, Revista Internacional del Trabajo, (33-1) 2014, p. 173.

5 TOMEI, Manuela y BELSER, Patrick, "Nuevas normas de la OIT sobre trabajo decente para los trabajadores domésticos", Revista Internacional del Trabajo, vol. 130, (3-4), 2011.

${ }^{6}$ Acertadamente GRAU PINEDA, Carmen, "De sirvientas a trabajadoras: la necesaria ratificación del Convenio 189 OIT sobre trabajo decente para las trabajadoras y los trabajadores domésticos", Lex Social Revista De Derechos Sociales, Vol. 9, núm. 2/2019, p. 50.

${ }^{7} \mathrm{Al}$ respecto queremos destacar el profundo estudio realizado por GÓMEZ RUFIÁN, Luis, "Características personales y condiciones jurídico-laborales del empleo doméstico en España: estudio a través de los microdatos de la encuesta de población activa”, en Lex Social: Revista De Derechos Sociales, 2019-9(2), pp. $115-153$. 
la carencia de un sistema normativo protector en materia preventiva: en primer lugar, se trata de un trabajo afectado por un alto grado de informalidad con porcentajes de no afiliación a la Seguridad Social que alcanzan a un cuarto de los trabajadores del sector ${ }^{8}$; en segundo lugar, se trata de un sector con un destacadísimo nivel de ocupación femenina ${ }^{9}$; y en tercer lugar, se trata de trabajos realizados por un amplio número de mujeres migrantes o nacidas fuera de España, especialmente en el caso de las internas ${ }^{10}$. En cuanto al perfil jurídico-laboral queremos destacar los altos niveles de parcialidad, en su mayor parte involuntaria ${ }^{11}$.

\section{Las carencias del sistema normativo español en materia de seguridad y salud del trabajo doméstico}

De manera que, dadas las características del empleo doméstico -las funciones realizadas, el lugar en que se realizan, las condiciones de precariedad e informalidad que la acompañan-, y su desprotección generalizada, creemos que no es muy ambicioso reclamar una atención especialmente escrupulosa en materia de prevención de riesgos laborales.

El panorama es, sin embargo, desolador, en cuanto a la normativa interna se refiere. Las normas españolas, al menos hasta el momento, se han inhibido de abordar seriamente la prevención de los riesgos laborales en el trabajo doméstico, y en este sentido debemos destacar principalmente la ausencia de atención por la Ley de Prevención de Riesgos Laborales (LPRL), lo que deviene un incumplimiento de la obligación de los poderes públicos de velar por la seguridad e higiene en el trabajo, que, como principio rector de la política social, impone el art. 40 de la Constitución Española ${ }^{12}$. Como se ha señalado ${ }^{13}$,

\footnotetext{
${ }^{8}$ La afiliación ha oscilado "entre el 43,33\% de 2008 y el 75,90\% de 2017. No obstante aunque una cuarta parte de los trabajadores del sector siga en situación de informalidad, sí que se aprecian dos tendencias en cuanto al cambio normativo (...) operado en 2010: por un lado, que el mismo generó importantes incentivos para la el afloramiento y regularización de un amplio montante de trabajadoras del sector; y, por el otro, que, no obstante, dicho impulso apenas duró algo más de los dos años iniciales de vigencia del nuevo régimen de Seguridad Social, pues ya desde 2013 pero finalmente desde 2014, se estanca el porcentaje de trabajadoras regularizadas", GÓMEZ RUFIÁN, Luis, "Características personales y condiciones jurídico-laborales del empleo doméstico en España...”, obra citada, pp. 122-123. ${ }^{9}$ De acuerdo con los datos extraídos de la encuesta de población activa en el primer trimestre de 2021, la tasa de feminización del sector era de un $89,4 \%$; ya que integraban este sector un total de 556.300 personas trabajadoras, de las cuales solo 58.900 eran hombres. En cambio, en el mismo período, los datos ponen de manifiesto que del total de ocupados en el mercado de trabajo español la tasa de feminización es del 45,9\%. ${ }^{10} \mathrm{Si}$ tomamos en consideración los datos de Afiliación a la Seguridad Social en alta laboral en 2019, en el epígrafe 97 "Actividades de los hogares como empleadores de personal doméstico" la media anual es de un $39,1 \%$ de trabajadores afiliados extranjeros, frente a un $10,9 \%$ de porcentaje total de trabajadores extranjeros.

${ }^{11}$ La consulta de los datos de la EPA en los años 2019 y 2020 permite reconocer una media anual de parcialidad en el sector doméstico de un $55 \%$ (frente a un $14 \%$ de parcialidad en el conjunto empleo asalariado en el mismo periodo).

12 SANZ SÁEZ, Concepción. "La exclusión de la prevención de riesgos laborales de la relación laboral especial del trabajo doméstico: análisis crítico de las posibles razones”, Lan Harremanak, 44, 2020, p. 81. 13 SANZ SÁEZ, Concepción, "La discriminación en contra de las empleadas de hogar como forma de manifestación de las discriminaciones múltiples”, en Revista de Derecho Social, núm. 83, 2018, p. 99.
} 
justificar la exclusión tomando en consideración el lugar de trabajo carece de consistencia, ya que otros trabajos con esta misma característica, como la prestación de servicios a domicilio, no han sido excluidos. Que la ausencia de regulación se deba a dificultades en la aplicación de normativas preventivas en el interior de los hogares familiares tampoco parece suficiente justificación, más allá de la falta de verdadera voluntad de protección preventiva de las trabajadoras domésticas.

Efectivamente, el artículo 3.4 de la LPRL señala al respecto que la LPRL no "será de aplicación a la relación laboral de carácter especial del servicio del hogar familiar" y únicamente encomienda al titular del hogar familiar la genérica obligación de "cuidar de que el trabajo de sus empleados se realice en las debidas condiciones de seguridad e

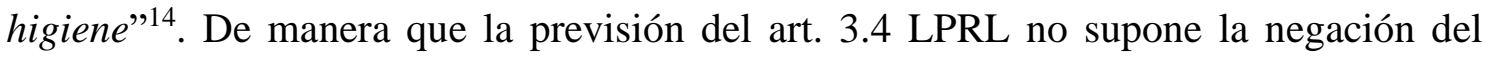
derecho a la seguridad y salud laboral, aunque sí la inaplicación de la principal norma en materia de prevención de riesgos laborales ${ }^{15}$. Si compartimos que el objetivo de la LPRL es promover la seguridad y salud de los trabajadores mediante la aplicación de medidas y el desarrollo de actividades para la prevención de riesgos derivados del trabajo, así como que la ley regula las actuaciones a desarrollar por administraciones públicas, empresarios y trabajadores y sus organizaciones representativas (art. 2.1 LPRL), no puede desconocerse que estamos ante una norma que excluye de la adecuada prevención a los trabajos domésticos realizados en el ámbito de los hogares familiares, a los que no adapta el contenido de las obligaciones preventivas en modo alguno ${ }^{16}$. La exclusión de la norma

\footnotetext{
${ }^{14}$ Conviene precisar que la LPRL con esta exclusión se alinea con el art. 3 de la Directiva 89/391/CEE de 12 de junio, relativa a la aplicación de medidas para promover la mejora de la seguridad y de la salud de los trabajadores en el trabajo, que al delimitar su ámbito de aplicación expresamente señala que es "trabajador: cualquier persona empleada por un empresario, incluidos los trabajadores en prácticas y los aprendices, con exclusión de los trabajadores al servicio del hogar familiar"; en el mismo sentido SANZ SÁEZ, Concepción. "La exclusión de la prevención de riesgos laborales de la relación laboral especial del trabajo doméstico: análisis crítico de las posibles razones", citado, p. 88.

${ }^{15}$ Desde la preocupación por la exclusión de la LPRL y con la finalidad de facilitar la prevención de riesgos laborales en el trabajo doméstico se han ido editando Guías de Prevención de Riesgos Laborales para los Trabajadores Domésticos por distintos sujetos, entre los que destacan diversos gobiernos autonómicos: así, por ejemplo, en 2019 se publica por parte del OSALAN-Instituto Vasco de Seguridad y Salud laboral la Guía básica de prevención de riesgos laborales para personas trabajadoras del hogar, que incluye una serie de recomendaciones preventivas básicas para evitar riesgos, con información destinada tanto a empleadores como a personas trabajadoras del hogar. Puede consultarse en https://www.osalan.euskadi.eus/libro/guia-basica-de-prevencion-de-riesgos-laborales-para-personastrabajadoras-del-hogar-2019/s94-contpub/es/. Por su parte, el Instituto Andaluz de Prevención de Riesgos Laborales publicó en 2010 la Guía de Prevención de Riesgos Domésticos, https://www.juntadeandalucia.es/export/drupaljda/1_2108_guia_prd.pdf

También desde la acción sindical se han realizado Guías informativas y estudios en torno a la prevención de riesgos de empleadas de hogar o de atención domiciliaria. Algunos ejemplos desde UGT, CCOO o USO: http://www.ugt.cat/download/salut_laboral/documents_sectorials_de_prevenció_de_riscos/profesionales $\% 20 \mathrm{de} \% 201 \mathrm{a} \% 20$ atención\%20domiciliaria.pdf https://construccionyservicios.ccoo.es/2d29c5d658bfaa7d80b588382c8f0f4d000072.pdf http://www.uso.es/wp-content/uploads/2017/01/Gu\%C3\%ADa-Empleadas-de-hogar-2016-web.pdf

${ }^{16}$ Lo que, de hecho, va a tener como consecuencia la práctica total inaplicación del derecho a la seguridad y salud laboral, en una relación laboral no exenta de riesgos. Sobre la cuestión LENZI, Olga, "Trabajo
} 
supone no sólo la eliminación del conjunto de obligaciones preventivas del empleador y del reconocimiento del derecho a una protección eficaz de los trabajadores respecto a todos los riesgos laborales y, en consecuencia, también la supresión del conjunto de elementos de garantía de la prevención de riesgos laborales, como la evaluación de riesgos (art. 16 LPRL), la adaptación de equipos y métodos de trabajo (art. 17 LPRL), la formación de las personas trabajadoras (art. 19 LPRL), la planificación preventiva, la vigilancia de su cumplimiento por parte de la Inspección de Trabajo y Seguridad Social, que incluye las importantes labores de asesoramiento e información (art. 9 LPRL), y en general, la vigilancia de la salud de los trabajadores domésticos respecto a los riesgos inherentes al trabajo (art. 22 LPRL).

Tampoco el RD 1620/2011 mejora la atención a la prevención de riesgos laborales en el trabajo doméstico, ya que únicamente dedica el art. 7.2 y solamente para señalar que " $\mathrm{el}$ empleador está obligado a cuidar de que el trabajo del empleado de hogar se realice en las debidas condiciones de seguridad y salud, para lo cual adoptará medidas eficaces, teniendo debidamente en cuenta las características específicas del trabajo domésticos. El incumplimiento grave de estas obligaciones será justa causa de dimisión del empleado".

Es decir, del tenor literal del art. 7.2 del RD 1620/2011 podemos identificar una obligación de seguridad del empleador, pero de contornos muy ambiguos e indeterminados, nada delimitados ni de los que aparentemente se puedan derivar obligaciones preventivas, ni más consecuencia que la dimisión del empleado en supuestos de deficiencia grave. De forma que, más allá de establecer esta obligación de adecuación del lugar de trabajo a las condiciones de seguridad e higiene, cabe destacar que la deficiencia grave en el cumplimiento de esta obligación ni siquiera es considerada por el $\mathrm{RD}$ un incumplimiento grave del empleador que pudiera dar lugar a una extinción indemnizada por parte del empleado, al amparo del art. 50.1.c $\mathrm{ET}^{17}$, lo que puede ser un indicio de la importancia que se está dando a la cuestión de la prevención de riesgos en el trabajo doméstico. En nuestra opinión, el incumplimiento grave de los deberes de seguridad e higiene en el trabajo debería haberse vinculado claramente a la extinción indemnizada del contrato regulada en el art. 50.1.c del ET, por la entidad y relevancia del incumplimiento y su repercusión en la salud de las personas trabajadoras del hogar.

\section{Dos elementos adicionales: la falta de negociación colectiva y las dificultades de control}

Concurren, además, dos características en las prestaciones de servicios en el hogar familiar que pueden tener repercusión en las carencias existentes en la protección de su

doméstico decente: ¿una combinación alcanzable en España?”, en El futuro del trabajo: cien años de la OIT, Ministerio de Trabajo, Migraciones y Seguridad Social, Madrid, 2019, pp. 259-260.

17 SANZ SÁEZ, Concepción. "La exclusión de la prevención de riesgos laborales de la relación laboral especial del trabajo doméstico: análisis crítico de las posibles razones”, citado, p. 90. 
salud laboral, como son, de una parte, las dificultades para ejercer en el ámbito del trabajo doméstico los derechos laborales colectivos, y de otra, las dificultades de control de la Inspección de Trabajo ${ }^{18}$.

Por lo que hace a la primera, todos los derechos laborales colectivos, sin excepción, vienen reconocidos a los trabajadores domésticos en el art. 7 del RD 1620/2011, por la vía de la remisión a los derechos previstos en el art. 4 del Estatuto de los Trabajadores. Entre ellos hemos de destacar el derecho a la negociación colectiva, considerada de modo unánime como una herramienta extraordinariamente útil para la protección de los derechos de los trabajadores domésticos ${ }^{19}$, dado que, en nuestro caso, puede servir para regular aquellas cuestiones que el $\mathrm{RD}$, que otorga al convenio colectivo una condición de fuente de los derechos y obligaciones en esta relación laboral, no aborda en profundidad ${ }^{20}$.

Sin embargo, este paso no se ha dado hasta ahora. El reconocimiento de derechos no implica necesariamente su ejercicio, y así ocurre en el caso del trabajo doméstico, dado que la norma especial, el RD 1620/2011, no los regula expresamente y la aplicación de las normas generales no lo facilita. Así, la ausencia de convenios colectivos aplicables en el sector de trabajo doméstico es una realidad en nuestro país, lo que impide contar por esa vía con una mínima regulación de las medidas que integrarían las obligaciones preventivas del empleador en la relación de trabajo doméstico.

Las razones de esta ausencia de convenio colectivo son varias, que empiezan desde la base, es decir, con las dificultades que han tenido las trabajadoras del hogar para integrarse en organizaciones sindicales por las que tradicionalmente han sentido desafección y a las que poco aportan en términos de medición de su representatividad ${ }^{21}$. Aunque en la actualidad pueden encontrarse en el panorama español organizaciones

\footnotetext{
${ }^{18}$ QUINTERO LIMA, Gema, "Salud laboral de las empleadas de hogar: una aproximación de urgencia", en (BLÁZQUEZ AGUDO, Eva, (Dir.), Informe sobre la salud laboral desde la perspectiva de género, Universidad Carlos III de Madrid, 2017, p. 97-98.

${ }^{19}$ OELZ, Martin, "El Convenio y la Recomendación de la OIT sobre las trabajadoras y los trabajadores domésticos. Una oportunidad para la justicia social", citado, p. 187; HOBDEN, Claire, "Improving working conditions for domestic workers: organizing, coordinated action and bargaining", Issue Brief $\mathrm{n}^{\circ} 2$, INWORK, International Labour Office, 2015, p. 2.

${ }^{20}$ BLASCO MARTÍN, Elena, "Contribución especial: pequeño cuestionario para la acción sindical en el sector del trabajo doméstico", en Lex social: Revista de Derechos Sociales, vol. 9, nº 2, 2019, pp. 415-416, donde reconoce que "sería un gran avance para reglamentar la actividad"; NIETO ROJAS, Patricia, "Trabajo doméstico y derechos colectivos. Algunas reflexiones al hilo del RD 1620/2011 y del Convenio 189 OIT", en Lex social: Revista de Derechos Sociales, vol. 9, n 2, 2019, p. 404; BENAVENTE TORRES, $\mathrm{M}^{\mathrm{a}}$ Inmaculada, "Dificultades para la negociación colectiva en el ámbito de la relación laboral especial del trabajo al servicio del hogar familiar", en Lex Social; Revista de Derechos Sociales, 11 (1), 2021, pp. 540542.

${ }^{21}$ BENAVENTE TORRES, M ${ }^{a}$ Inmaculada, "Dificultades para la negociación colectiva en el ámbito de la relación laboral especial del trabajo al servicio del hogar familiar", citado, pp. 543-544, identifica acertadamente como causas de esta desafección el aislamiento y la feminización del sector, la identificación con el empleador, el alto grado de parcialidad en los trabajos, la presencia de inmigrantes en situación irregular, el alto porcentaje de empleo oculto y la facilidad del empleador para desistir de la relación dándola por finalizada.
} 
sindicales de rama que representan los intereses del colectivo ${ }^{22}$, hasta ese momento lo que ha predominado ha sido el movimiento asociativo ${ }^{23}$, sin legitimación para negociar convenios colectivos.

Aun así, la existencia actualmente de sindicatos de rama tampoco garantiza que puedan participar en la negociación colectiva en el sector ya que, para que contaran con legitimación, sería necesario adaptar la medición de su representatividad a sus concretas características $^{24}$, pues el criterio utilizado por nuestro legislador, la audiencia electoral, les impide obtener la condición de sujetos legitimados. De este modo, sólo las organizaciones sindicales más representativas pueden hoy negociar convenios colectivos para el trabajo doméstico, sorprendiendo negativamente su inactividad en este terreno ${ }^{25}$.

En relación con la segunda de las características, la labor de control del cumplimiento de las medidas preventivas realizable por la Inspección de Trabajo y Seguridad Social (ITSS) en el hogar familiar considerado como centro de trabajo, se pone especial énfasis en el derecho a la intimidad personal y familiar y en la inviolabilidad del domicilio (previstos constitucionalmente en los apartados 1 y 2 del art. $18 \mathrm{CE}^{26}$ ), como límites al ejercicio de control por la autoridad laboral. Sin embargo, apenas se contemplan alternativas, ni modos de ejercicio del control sin vulneración de tales derechos fundamentales, lo que, en ningún caso, puede convertirse en una exclusión absoluta de la aplicación de normas preventivas $^{27}$. En este sentido, contrasta el análisis de las facultades de la ITSS respecto a la entrada en centros de trabajo o en hogares familiares, desarrolladas en el art. 13 de la Ley 23/2015, de 21 de julio, Ordenadora del Sistema de Inspección de Trabajo y

\footnotetext{
22 Por ejemplo, el Sindicato Independiente de Trabajadoras del Hogar y los Cuidados Sindihogar/Sindillar, creado en Barcelona en 2011; o más recientemente, en enero de 2021, el Sindicato de Trabajadoras de Hogar y Cuidados, SINTRAHOCU, organización sindical de ámbito estatal.

${ }^{23}$ Con asociaciones como ATH-ELE (Asociación de Trabajadoras del Hogar de Bizkaia), en activo desde 1986 y que dispone de un servicio de asesoría legal gratuito y realiza labores de formación e información del colectivo; o como SEDOAC (Servicio Doméstico Activo) que desde 2005 está desarrollando acciones y campañas de sensibilización, trabajo en red, incidencia política y empoderamiento de las trabajadoras domésticas.

${ }^{24}$ BENAVENTE TORRES, Ma Inmaculada, "Dificultades para la negociación colectiva en el ámbito de la relación laboral especial del trabajo al servicio del hogar familiar”, citado, p. 544.

${ }^{25} \mathrm{Y}$ es que desde 2011, con la reforma de los arts. 87 y 88 del Estatuto de los Trabajadores por RDLey 7/2011, de 10 de junio, la inexistencia de organizaciones, tanto sindicales como patronales, con suficiente representatividad en el ámbito del convenio ha dejado de ser obstáculo para la negociación de convenios sectoriales. Por tanto, desde ese momento se han podido negociar convenios colectivos estatutarios para el sector de trabajo doméstico. Sobre los problemas que esta posibilidad pueda traer consigo, y manifestando su discrepancia con esta opinión generalizada, véase BENAVENTE TORRES, $\mathbf{M}^{\mathrm{a}}$ Inmaculada, "Dificultades para la negociación colectiva en el ámbito de la relación laboral especial del trabajo al servicio del hogar familiar", citado, pp. 546 y ss.

${ }^{26}$ Señala el apartado 1 del art. 18 de la CE que: "Se garantiza el derecho al honor, a la intimidad personal y familiar y a la propia imagen.", manteniendo el apartado 2 del mismo artículo: "El domicilio es inviolable. Ninguna entrada o registro podrá hacerse en él sin consentimiento del titular o resolución judicial, salvo en caso de flagrante delito".

${ }^{27}$ SANZ SÁEZ, Concepción. "La exclusión de la prevención de riesgos laborales de la relación laboral especial del trabajo doméstico: análisis crítico de las posibles razones”, citado, pp. 81-82 y 94 y ss.
} 
Seguridad Social, que en su labor inspectora puede "entrar libremente en cualquier momento y sin previo aviso en todo centro de trabajo, establecimiento o lugar sujeto a inspección y a permanecer en el mismo", pero que, por el contrario, "si el centro sometido a inspección coincidiese con el domicilio de una persona física, deberán obtener su expreso consentimiento o, en su defecto, la oportuna autorización judicial.".

Como se sabe, el art. 12 del RD 1620/2011 atribuye el control del cumplimiento de la legislación laboral de esta relación laboral a la ITSS; sin embargo, parece que no está siendo fácil el hallazgo de fórmulas por las que este organismo realice la labor de vigilancia sin atentar a los mencionados derechos de inviolabilidad de domicilio y de intimidad personal y familiar (art. 18.1 y $2 \mathrm{CE}$ ). Esta circunstancia puede crear en los empleadores la sensación de impunidad derivada de la impresión de inexistencia de controles o sanciones ${ }^{28}$.

No obstante, queremos dejar constancia del Plan de actuación de la Inspección de Trabajo y Seguridad Social en el sector del hogar que ha iniciado la ITSS en enero de 2021. En este Plan se señalan como principales líneas de acción: la lucha contra la economía irregular, dando prioridad a las denuncias presentadas y comunicaciones recibidas en el Buzón de la Inspección de Trabajo y Seguridad Social; la asistencia técnica y sensibilización, tanto a empleadores como a personas trabajadoras del sector y la regularización de salarios por debajo del SMI, y correlativa regularización de cotizaciones a la seguridad social ${ }^{29}$.

Sin duda el acceso al hogar familiar es una de las mayores dificultades que la Inspección puede encontrar en su labor de control, pues el sistema de denuncias y comunicaciones en el Buzón de la ITSS puede resultar insuficiente. En esta línea, un ejemplo de buenas prácticas para la detección de trabajo doméstico irregular o informal es el puesto en marcha por Uruguay 30: "El Gobierno indica que, en el supuesto de denuncia, existe un protocolo, de acuerdo al cual cuando se realiza una denuncia por presunto trabajo doméstico informal, automáticamente se visita el hogar denunciado, así como otros

\footnotetext{
${ }^{28}$ LENZI, Olga, “Trabajo doméstico decente: ¿una combinación alcanzable en España?”, citado, p. 261.

${ }^{29}$ https://www.mites.gob.es/itss/web/Documentos/CAMPANA_Servicio_HOGAR/index.html. Para ello la ITSS se ha dirigido a los empleadores de empleados de hogar cuyos datos constan en la TGSS y cuyas retribuciones no consta que se hayan actualizado al SMI vigente a efectos de que declaren el salario real. Para su actualización se fija como periodo hasta el 30 de marzo de 2021; transcurrido dicho periodo, a partir de 1 de abril de 2021 se inician las actuaciones inspectoras de comprobación por la ITSS y la posible imposición de sanciones. De acuerdo con los datos publicados se ha realizado el envío de 47.749 cartas, que alertaban de irregularidades en la situación salarial o de cotización, y 28.904 personas empleadas de hogar han visto actualizados sus salarios y cotizaciones a la Seguridad Social (https://www.lamoncloa.gob.es/serviciosdeprensa/notasprensa/trabajo14/Paginas/2021/090421hogar.aspx ).

${ }^{30}$ Puede consultarse en la información publicada por la OIT como consecuencia de la labor de Control de la aplicación de las Normas Internacionales del Trabajo, en concreto del Convenio 189-OIT ratificado en 2012 por Uruguay

https://www.ilo.org/dyn/normlex/es/f?p=NORMLEXPUB:13100:0::NO::P13100_COMMENT_ID:39601 $\underline{36}$
} 
hogares de la zona. De esta manera, se consigue un doble objetivo, realizar inspecciones en un mayor número de hogares y no exponer al denunciante".

\section{Riesgos laborales y trabajo doméstico}

No podemos finalizar este planteamiento introductorio sin poner de manifiesto que por las actividades realizadas por los trabajadores domésticos se produce la exposición a riesgos específicos derivados tanto de las tareas desarrolladas en el puesto de trabajo ${ }^{31}$, como de los vinculados al peculiar lugar de trabajo -el hogar o los hogares familiares-.

Los estudios señalan la posible concurrencia de riesgos físicos- "largas jornadas de trabajo, tiempo de descanso insuficiente y, en ocasiones, comida insuficiente, exposición al agua caliente y fría, exposición al ambiente caluroso de la cocina, problemas musculosqueléticos, sobre todo de la espalda y la columna, originados por cargar a los niños, mover los muebles y arrodillarse para limpiar el suelo"-; riesgos químicos "exposición a ácidos, álcalis, disolventes; falta de formación sobre los materiales utilizados o manipulados"-; riesgos biológicos -especialmente en el cuidado de personasy riesgos psicológicos y estrés ${ }^{32}$.

En efecto, junto a los riesgos físicos, químicos o biológicos, es preciso referirse a la repercusión de los riesgos psicosociales en el trabajo doméstico ${ }^{33}$. Éstos pueden venir derivados tanto de las condiciones en que se realizan esos servicios (lugar de prestación, tareas realizadas y condiciones de trabajo, especialmente en el caso de los trabajadores internos) y del hecho de tratarse de un colectivo especialmente vulnerable por sus elevados índices de informalidad y precariedad; pero también por las características personales de quienes los prestan al tratarse de un empleo profundamente feminizado (el $89.4 \%$ es desempeñado por mujeres), y altamente constituido por población migrante (39.1\% del total).

Algunas de las medidas de prevención de los riesgos señalados pueden derivarse de la especial vigilancia en el cumplimiento de la normativa laboral: así, por ejemplo, todos los riesgos relacionados con la necesidad de transformación en trabajo formal -especialmente en el caso de trabajadoras migrantes-; o las relativas al tiempo de trabajo y descanso. Pero otras medidas de protección requieren de acciones específicas, esto es, de la adopción de normativa preventiva adecuada al trabajo doméstico: formación e información sobre los

\footnotetext{
${ }^{31}$ Se plantea al respecto extrapolar las reglas generales sobre manipulación de cargas, sobre trabajos en altura, sobre uso y multiexposición a determinados productos químicos, o sobre realización de tareas repetitivas. Aunque se advierte que esta extrapolación "solo permite identificar riesgos y señalar medidas preventivas, pero de facto no ofrece alternativas para resolver las dificultades materiales aplicativas", QUINTERO LIMA, Gema, "Salud laboral de las empleadas de hogar: una aproximación de urgencia", citado, p. 102.

${ }^{32}$ BABIN, Angela, «Servicios personales y comunitarios: Empleados del hogar», en: Enciclopedia de salud y seguridad en el trabajo, Angela Babin (dir.), v.3, n.100, 2001, pp. 16-21. [en línea]. Consultado en: https://www.insst.es/tomo-iii

33 Véase CORREA CARRASCO, Manuel, "Los riesgos psicosociales en el trabajo doméstico y de cuidados", Lex Social: Revista De Derechos Sociales, Vol. 11(1), 2021, p. 433.
} 
riesgos físicos, químicos y biológicos a los trabajadores y empleadores; vigilancia, prevención y protección de la violencia y acoso de colectivos especialmente vulnerables por su aislamiento en el lugar de trabajo...

En este sentido es importante poner de manifiesto la necesidad de abordar la prevención de riesgos en el trabajo doméstico desde una perspectiva de género en la línea señalada por la Estrategia española sobre seguridad y salud en el trabajo 2015-2020, prorrogado por Acuerdo del Consejo de Ministros de fecha 23 de febrero de 2021, que se refiere a la necesidad de "promover un enfoque de género en las actividades preventivas, que permita detectar particularidades y garantizar su protección"34.

Así se pone de relieve en el Estudio para la detección de riesgos psicosociales en el Trabajo del Hogar realizado por $\mathrm{CCOO}^{35}$, en el que se señalan como factores de riesgos psicosociales la inseguridad sobre las condiciones de trabajo, la inseguridad sobre el empleo, la falta de trato digno, la sobrecarga de tareas, el ritmo de trabajo, el desgaste emocional en las labores de cuidado, la doble presencia, la falta de reconocimiento del trabajo, la maternidad y la violencia en el trabajo y el acoso sexual ${ }^{36}$-que al producirse en el hogar familiar convierte en más vulnerables a las trabajadoras- ${ }^{37}$.

\section{Convenios OIT, ODS y trabajo decente}

Todos estos presupuestos nos permiten plantear la imperiosa necesidad de ratificación e incorporación al ordenamiento español de dos Convenios de la OIT: el Convenio 189 (y la Recomendación 201) sobre el trabajo decente para las trabajadoras y los trabajadores domésticos, del año 2011, y el Convenio 190 (y la Recomendación 206) sobre la violencia y el acoso en el trabajo, del año $2019^{38}$. Y ello no sólo para la correcta integración de la

34 https://www.insst.es/documents/94886/599872/Plan+de+accion+2019-2020.pdf/4e97c156-297b-4116$\underline{8181-7 \mathrm{~b} 8 \mathrm{e} 6 \mathrm{a} 296 \mathrm{fbc}}$

$\frac{81}{35}$ En efecto, sobre la cuestión es preciso consultar el exhaustivo análisis realizado por CCOO de Construcción y Servicios, Estudio para la detección de riesgos psicosociales en el Trabajo del Hogar AS2018-0012, Madrid, Ministerio de Trabajo, Migraciones y Seguridad Social, 2019. [en línea]. Consultado en: https://construccionyservicios.ccoo.es/2d29c5d658bfaa7d80b588382c8f0f4d000072.pdf

${ }^{36}$ Los estudios realizados ponen de manifiesto la mayor incidencia de la violencia en las trabajadoras domésticas migrantes: BOFILL POCH, Silvia y VÉLIZ TORRESANO, Norma, Una violència oculta assetjament sexual en dones migrades treballadores de la llar $i$ les cures, 2019, disponible en https://irla.cat/wp-content/uploads/2019/05/BECA-YARZA-una-violencia-oculta-web.pdf acreditan que: "El $41 \%$ de les dones afirma haver estat objecte de grolleries - insinuacions, proposicions o comentaris de caràcter sexual; el $28 \%$ haver estat objecte de tocaments o d'apropaments excessius - tocaments, fregaments, pessics; el 10\% haver rebut demandes de relacions sexuals, sota pressió o no; i el 10\% afirma que han abusat sexualment d'elles" (p. 33); también identifican el perfil de la persona acosadora más habitual: "El perfil més habitual de la persona que assetja la treballadora de la llar és la d'un home gran ja sigui vidu, casat o solter - que contracta la treballadora per feines de cura, pròpia o d'algun familiar, i/o neteja de la casa, directament o a través d'una empresa" (p. 71).

${ }^{37} \mathrm{CCOO}$ de Construcción y Servicios, Estudio para la detección de riesgos psicosociales en el Trabajo del Hogar, citado, pp. 105-111 y 115 y ss.

${ }^{38}$ Debe en todo caso ponerse de manifiesto que, para los países miembros de la UE, de acuerdo con las previsiones del TUE, los Estados no podían ratificar el Convenio 190 sin la previa autorización del Consejo, ya que tanto la discriminación entre hombres y mujeres en el empleo y la ocupación, como la prevención 
prevención de riesgos laborales en el trabajo doméstico, sino también para la adecuada prevención, tratamiento y protección frente a la violencia y acoso en el trabajo doméstico, especialmente de las trabajadoras domésticas.

Y además queremos resaltar que este planteamiento puede vincularse con el contexto de la Agenda 2030 y los ODS, especialmente en cuanto hace referencia a la salud y el bienestar (ODS 3), a la igualdad de género (ODS 5) y al trabajo decente (ODS 8), para lo cual deviene esencial la corrección de los déficits y desigualdades del trabajo doméstico y de cuidados $^{39}$. Es en 2015 cuando los Estados Miembros de las Naciones Unidas aprobaron los 17 Objetivos de Desarrollo Sostenible como parte de la Agenda 2030 para el Desarrollo Sostenible. Se trata de un llamamiento universal a la acción para poner fin a la pobreza, proteger el planeta y mejorar las vidas y las perspectivas de las personas en todo el mundo. La meta 4 del ODS 5 se refiere literalmente a "Reconocer y valorar los cuidados y el trabajo doméstico no remunerados mediante servicios públicos, infraestructuras y políticas de protección social, y promoviendo la responsabilidad compartida en el hogar y la familia, según proceda en cada país". Aunque se pone el acento en el trabajo doméstico no remunerado, es preciso recordar que éste es considerado uno de los indicadores más desiguales y generadores de una de las más elevadas brechas entre géneros, por lo que se requiere una estrategia de inversión efectiva en los servicios de cuidados sin ignorar la importancia de incorporar una perspectiva de género en su implementación ${ }^{40}$.

\section{Salud, trabajo doméstico y Convenio 189-OIT}

En su 100a reunión (2011), la Conferencia Internacional del Trabajo adoptó el Convenio sobre el trabajo decente para las trabajadoras y los trabajadores domésticos (núm. 189) y la Recomendación sobre el trabajo decente para las trabajadoras y los trabajadores domésticos (núm. 201), aprobación que fue calificada de hecho histórico y conquista social $^{41}$. Este Convenio -tratado internacional jurídicamente vinculante, previa

de riesgos laborales entran dentro de las competencias normativas de la UE. La Propuesta de Decisión del Consejo de 22 de enero de 2020 autoriza a los Estados miembros a ratificar, en interés de la UE, el Convenio sobre la violencia y el acoso, 2019 ( $n^{\circ}$ 190) de la OIT. España ha anunciado el inicio del proceso de ratificación. Sobre la cuestión OLARTE ENCABO, Sofía, "Los principios fundamentales del Convenio 190 OIT: un análisis desde la perspectiva de género. La novedosa inclusión del trabajo de servicio doméstico", en CORREA CARRASCO/QUINTERO LIMA (DIRS.), Violencia y acoso en el trabajo. Significado y alcance del Convenio $n^{\circ} 190$ OIT en el marco del trabajo decente (ODS 3,5,8 de la Agenda 2030), DYKINSON, Madrid, 2021, p. 74.

${ }^{39}$ GRAU PINEDA, Carmen, "De sirvientas a trabajadoras...”, citado, p. 54. Vid también QUINTERO LIMA, Gema, "Las violencias del trabajo", en CORREA CARRASCO/QUINTERO LIMA (DIRS.), Violencia y acoso en el trabajo. Significado y alcance del Convenio $n^{\circ} 190$ OIT en el marco del trabajo decente (ODS 3,5,8 de la Agenda 2030), citado, pp. 307-317.

${ }^{40}$ GRAU PINEDA, Carmen, "De sirvientas a trabajadoras...”, citado, p. 56.

${ }^{41}$ QUESADA SEGURA, Rosa, "La dignificación del trabajo doméstico. El convenio n 189, OIT, 2011", en Revista General de Derecho del Trabajo y de la Seguridad Social, (27), 2011, p. 2 (versión electrónica). 
ratificación de los Estados miembros ${ }^{42}$ - y la Recomendación 201 que lo complementa aunque sin carácter vinculante, proporciona pautas de orientación para la puesta en práctica del Convenio-, representan un punto de inflexión en lo que concierne a la protección de los derechos de los trabajadores domésticos y brindan una oportunidad para corregir la tradicional carencia o ausencia total de políticas públicas al respecto ${ }^{43}$.

El Convenio 189-OIT y la Recomendación 201 son instrumentos muy especiales, muestra de un modelo regulatorio construido "desde abajo hacia arriba", dada la especial implicación en su creación de las trabajadoras a quienes van destinados ${ }^{44}$. Estas trabajadoras, organizadas colectivamente, en un principio, en torno a entidades diversas -religiosas, sindicales, de trabajadores migrantes e, incluso, grupos feministas- hasta la creación de sus propias confederaciones regionales e internacionales, acabarán poniendo en la agenda de la OIT, en el marco de su promoción del trabajo decente ${ }^{45}$, y mediante alianzas con sindicatos y ONGs internacionales, la discusión y adopción de una regulación específica para el trabajo doméstico, adquiriendo un protagonismo tal en el proceso de creación de ambos instrumentos que les permitirá encontrarse presentes en las Conferencias Internacionales del Trabajo de 2010 y de 2011, en la que finalmente resulta aprobado.

\footnotetext{
${ }^{42}$ En abril de 2021, tan sólo 31 Estados han ratificado el Convenio 189 OIT, no encontrándose España entre ellos, a pesar de que existe una Decisión del Consejo de 28 de enero de 2014 por la que se autoriza a los Estados miembros a ratificar, en interés de la Unión Europea, el Convenio sobre trabajo digno para los trabajadores domésticos de 2011, de la organización Internacional del trabajo (Convenio $n^{\circ} 189$ ). DOUE de 1 de febrero de 2014, L 32/32. La fecha de entrada en vigor del Convenio 189 OIT fue el 5 de septiembre de 2013.

${ }^{43}$ OELZ, Martin, "El Convenio y la Recomendación de la OIT sobre las trabajadoras y los trabajadores domésticos. Una oportunidad para la justicia social”, citado, p. 161.

${ }^{44}$ POBLETE, Lorena, La producción de estándares laborales para el trabajo doméstico. La traducción del Convenio 189 en tres países del Sur: Argentina, Sudáfrica y Filipinas, Ed. CLACSO, Buenos Aires, 2015, pp. 13-19 donde señala que "frente a los argumentos jurídicos respecto de los principios de la OIT, las trabajadoras domésticas propusieron narrativas individuales, historias de luchas donde aparecían claramente sus vulnerabilidades y fortalezas". Resulta recomendable la visión del documental "C189: Sabiduría Convencional" de Sisi Sojourner productions, 2012 (visto en http://vimeo.com/76353904)

${ }^{45}$ Con carácter general, OIT, Guía práctica para la incorporación sistemática del empleo y el trabajo decente. Aplicación a nivel de país, Ginebra, 2008, p. vii, dispone que trabajo decente "es el trabajo productivo para los hombres y las mujeres en condiciones de libertad, equidad, seguridad y dignidad humana. El trabajo decente supone que unos y otras tengan oportunidades para realizar una actividad productiva que aporte un ingreso justo, seguridad en el lugar de trabajo y protección social para los trabajadores y sus familias; que ofrezca mejores perspectivas de desarrollo personal y favorezca la integración social; que dé libertad a las personas para manifestar sus inquietudes, organizarse y participar en las decisiones que inciden en su vida; y que garantice la igualdad de oportunidades y de trato para todos". Con carácter específico sobre el trabajo doméstico, OIT, Trabajo decente para los trabajadores domésticos, Conferencia Internacional del Trabajo (99a reunión), 2010, p. 16: "Reglamentar sus condiciones de trabajo y proporcionarles una protección social supone reconocer no solamente la importancia económica del trabajo doméstico y los quehaceres que realizan en la familia, sino también la dignidad inherente a la actividad del cuidado del prójimo". Véase un análisis del concepto de trabajo decente en los textos de la OIT en LENZI, Olga, "Trabajo doméstico decente: ¿una combinación alcanzable en España?", citado, pp. 247-264.
} 
Además, el enfoque de derechos humanos presente en el texto del Convenio resulta especialmente innovador, desde su Preámbulo, donde se citan las principales normas internacionales elaboradas en el seno de las Naciones Unidas, a su art. 3.1, en el que se exige que los Estados miembros adopten medidas para asegurar la promoción y la protección efectiva de los derechos humanos de todos los trabajadores domésticos, conforme a lo establecido en el Convenio ${ }^{46}$.

La Recomendación 201, a su vez, incorpora en su texto las proposiciones relativas al trabajo decente para los trabajadores domésticos, discutidas y adoptadas en la misma Conferencia en la que se aprueba el convenio.

Ahora bien, atendiendo a su naturaleza de norma internacional y reconociendo las diversas realidades y posibilidades sociales y económicas de los Estados, el Convenio permite un cierto grado de flexibilidad con respecto a su aplicación, haciendo especial hincapié en que el diálogo social es el principio fundamental en el que ha de basarse el proceso de aplicación.

El Convenio es un fiel reflejo de la discusión suscitada durante el proceso de su creación entre la consideración del trabajo doméstico "como ningún otro" trabajo, lo que permitirá su regulación a través de regímenes laborales especiales, que pudieran ser más restrictivos que los ordinarios, y su simultánea consideración "como cualquier otro" trabajo, lo que implica la equiparación de quienes lo realicen con los trabajadores en general, garantizando su igualdad sustancial ${ }^{47}$. Esta dicotomía se observa en ambos instrumentos, con, de un lado, medidas que equiparan a los trabajadores domésticos con el resto de trabajadores, reconociéndoles un mínimo nivel de protección y derechos, integrado por condiciones de trabajo que no sean menos favorables que las que aplican a los trabajadores en general; pero, de otro, con medidas que también tienen en cuenta las peculiaridades de la actividad en que consiste el trabajo doméstico, entre estas últimas las que tienen que ver con la protección de la salud en el lugar de trabajo. Y esa dicotomía se proyecta, a su vez, sobre el texto del RD 1620/2011, como es sabido.

\section{La protección de la salud en el Convenio 189-OIT y la Recomendación 201}

El art. 13.1 del Convenio 189 reconoce el derecho de todo trabajador doméstico a un "entorno de trabajo seguro y saludable", lo que se corresponde con la obligación de todo Estado miembro de adoptar medidas eficaces para asegurar la seguridad y salud en el trabajo, "teniendo debidamente en cuenta las características específicas del trabajo doméstico". Tales medidas, continúa diciendo el art. 13 en su apartado 2, "podrán

\footnotetext{
${ }^{46}$ GRAU PINEDA, Carmen, "De sirvientas a trabajadoras: la necesaria ratificación del Convenio 189 OIT sobre trabajo decente para las trabajadoras y los trabajadores domésticos”, citado, p. 67, destaca la pertinencia de este enfoque, "dado que hay muchos derechos que son humanos y laborales, cual género y especie, y "la mejora de unos repercute sobre la de los otros, de ahi que cada vez más se fomente la interacción entre ambos ",".

${ }^{47}$ BLACKETT, Adele, "Introductory Note to the Decent Work for Domestic Workers Convention, 2011 (NO. 189) and Recommendation (NO. 201)", en 53 ILM 250 (2014).
} 
aplicarse progresivamente en consulta con las organizaciones más representativas de los empleadores y de los trabajadores, así como con organizaciones representativas de los trabajadores domésticos y con organizaciones representativas de los empleadores de los trabajadores domésticos, cuando tales organizaciones existan”.

Se observa en el texto del precepto la referencia expresa a las características específicas del trabajo doméstico -su consideración "como ningún otro"-, que habrán de condicionar, sin duda, las medidas eficaces para garantizar esos entornos de trabajo seguros y saludables que hayan de adoptar los Estados miembros tras ratificar el Convenio. Entre esas características, las que pueden condicionar especialmente esas medidas son el lugar donde se prestan los servicios, el hogar familiar, y el hecho de que su titular, empleador en esta relación, no es un empresario mercantil al uso ${ }^{48}$. También puede advertirse la llamada al diálogo social tripartito, como herramienta para la aplicación progresiva de dichas medidas.

Por su parte, dentro de la Recomendación 201, las proposiciones que conciernen a este art. 13 del Convenio ${ }^{49}$ son las previstas en el párrafo 4 , sobre reconocimientos médicos de los trabajadores domésticos, y el párrafo 19, sobre prevención de riesgos laborales.

Comenzando por la segunda (párrafo 19), las medidas que se recomienda adoptar a los Estados miembros tras la ratificación, salvo que ya estuvieran recogidas por sus ordenamientos, incluyen, de manera ejemplificativa:

a) eliminar o reducir al mínimo, en la medida de lo posible, los peligros y riesgos relacionados con el trabajo, para con ello proteger a los trabajadores domésticos, previniendo accidentes, enfermedades y muertes de los trabajadores, y promoviendo así la seguridad y salud en los hogares que constituyen un lugar de trabajo;

$b$ ) establecer un sistema de inspección suficiente y apropiado, y sanciones adecuadas en caso de infracción de la normativa en materia de prevención;

c) instaurar procedimientos para recopilar y publicar estadísticas sobre enfermedades y accidentes profesionales en el trabajo doméstico, y otras estadísticas consideradas útiles para la prevención de los riesgos y accidentes en el contexto de la seguridad y salud en el trabajo;

d) prestar asesoramiento en materia de seguridad y salud en el trabajo, incluyendo los aspectos ergonómicos y los equipos de protección;

e) desarrollar programas de formación y difundir orientaciones relativas a los requisitos en materia de seguridad y salud en el trabajo específicos del trabajo doméstico.

\footnotetext{
${ }^{48}$ OELZ, Martin, "El Convenio y la Recomendación de la OIT sobre las trabajadoras y los trabajadores domésticos. Una oportunidad para la justicia social”, citado, p. 184.

${ }^{49}$ Así lo establece la OIT en el documento "Trabajo Decente para las trabajadoras y los trabajadores Domésticos. Convenio núm. 189 y Recomendación núm. 201 en pocas palabras", Oficina Internacional del Trabajo, 2011, p. 32.
} 
Por su parte, en el párrafo 4 se recomienda a los Estados que consideren poner a disposición de los miembros de los hogares y de los trabajadores domésticos la información sobre salud pública de que dispongan con respecto a los principales problemas de salud y enfermedades que puedan suscitar la necesidad de someterse a reconocimientos médicos, y de información sobre los reconocimientos médicos voluntarios, tratamientos médicos y buenas prácticas de salud e higiene, en consonancia con iniciativas de salud pública destinadas a la comunidad en general; así como difundir información sobre las mejores prácticas en la materia, teniendo en cuenta el carácter especial del trabajo doméstico.

En materia de reconocimientos médicos, además, los Estados habrán de garantizar el respeto al principio de confidencialidad de los datos personales y la privacidad de los trabajadores domésticos, así como prevenir cualquier discriminación, y asegurar que no se les exija someterse a pruebas de detección de VIH o embarazo o revelar su estado (párrafo 3).

\section{La inexistente adaptación del ordenamiento español al contenido del Convenio 189 OIT y la Recomendación 201 en materia de protección de la salud}

España, en abril de 2021, no ha ratificado todavía el Convenio 189 OIT. Algo que se preveía como inmediato tras la aprobación del Convenio en $2011^{50}$ no se ha materializado aún ${ }^{51}$. Sin embargo, nuestra legislación presenta, como ya hemos apuntado, carencias que afectan al reconocimiento de los derechos del colectivo de trabajadoras domésticas, comprometiendo por tanto el cumplimiento por nuestro país del objetivo de trabajo decente de la Agenda 2030.

En efecto, como ya avanzamos, la exclusión del trabajo doméstico del ámbito de aplicación de la LPRL supone no sólo eliminar el reconocimiento del derecho a una protección eficaz de los trabajadores domésticos respecto a todos los riesgos laborales, sino también, más específicamente, suprimir en este ámbito el conjunto de obligaciones preventivas que, con carácter general, tienen los empresarios, como elementos de garantía de la prevención de riesgos laborales ${ }^{52}$, algunas de las cuales coinciden con las medidas propuestas por la OIT en la Recomendación 201, párrafo 19.

Concretamente, se trata de las medidas propuestas en el párrafo 19, apartados: a) sobre la protección de los trabajadores mediante la eliminación o minimización de los riesgos, con miras a prevenir accidentes, enfermedades o muertes, que coincide con la obligación de

\footnotetext{
${ }^{50}$ QUESADA SEGURA, Rosa, "La dignificación del trabajo doméstico. El convenio n 189, OIT, 2011”, citado, p.5.

${ }^{51}$ Denunciando este hecho, recientemente, por ejemplo, SANZ SÁEZ, Concepción, "La exclusión de la prevención de riesgos laborales de la relación especial del trabajo doméstico: análisis crítico de las posibles razones", citado, pp. 97-100; de la misma autora, "La precarización como realidad de mercado: la frontera entre el empleo doméstico y el trabajo de cuidados", en Lex Social, Vol. 11, n 1, 2021, pp. 527-528.

${ }^{52}$ Es decir, existen estas garantías en nuestro ordenamiento para el resto de los trabajadores en general, con excepción de algunas actividades (art. 3.2 LPRL), pero no para el trabajo doméstico en particular (art. 3.4).
} 
realizar una adecuada evaluación de los mismos y una planificación de la actividad preventiva, implantando y aplicando un plan de prevención de los riesgos laborales (art. 16 LPRL); $\boldsymbol{b}$ ) sobre el establecimiento de un sistema de inspección suficiente y apropiado, y de sanciones en caso de incumplimiento, lo que en nuestro ordenamiento se atribuye a la Inspección de Trabajo y Seguridad Social (art. 9 LPRL), encargada de vigilar y controlar el cumplimiento de las normas sobre prevención a través de sus actuaciones, así como de asesorar e informar a las empresas y trabajadores, entre otras funciones; d) y $\boldsymbol{e}$ ), sobre asesoramiento en la materia, inclusive sobre aspectos ergonómicos y equipos de protección, así como sobre el desarrollo de programas de formación, cuestiones acerca de las cuales la LPRL establece obligaciones del empresario en sus arts. 18 (información a los trabajadores sobre los riesgos existentes en la empresa y en cada puesto de trabajo y en cada función, así como sobre las medidas y actividades de protección y prevención aplicables a los mismos) y 19 (formación suficiente y adecuada a los trabajadores en materia preventiva).

Además, tampoco se aplica en el trabajo doméstico otra obligación empresarial en materia preventiva recogida en el art. 22 LPRL, la de vigilar periódicamente la salud de sus trabajadores en función de los riesgos inherentes al trabajo mediante la realización de reconocimientos médicos periódicos $\mathrm{y}$, en general, voluntarios ${ }^{53}$, sobre los que expresamente se incluyen consideraciones a seguir por los Estados, centradas en la puesta a disposición de información, en el párrafo 4 de la Recomendación 201, como ya hemos mencionado.

En principio, por tanto, la única medida de las propuestas en el párrafo 19 de la Recomendación 201 que tiene traslación a nuestro ordenamiento es la prevista en su apartado c) sobre la instauración de procedimientos de recopilación y publicación de estadísticas sobre enfermedades y accidentes profesionales relativos al trabajo doméstico, al extenderse al colectivo la acción protectora de las contingencias profesionales por Ley 39/2010, de 22 de diciembre, de Presupuestos Generales del Estado para 2011, de modo que desde 2012 se encuentran incluidas en las estadísticas sobre accidentes de trabajo ${ }^{54}$, y el índice de enfermedades profesionales en las actividades de los hogares como empleadores de personal doméstico se recoge a su vez en el informe estadístico anual sobre enfermedades profesionales del Observatorio de las Contingencias Profesionales de la Seguridad Social (CEPROSS) ${ }^{55}$.

\footnotetext{
${ }^{53}$ Señala ROMERAL HERNANDEZ, Josefa, "El impacto del Convenio 189 de la OIT en las condiciones de trabajo de los empleados de hogar", en Revista Aranzadi Social, n 7, 2013, p. 19, que el RD 1620/2011 "debía haber previsto la realización de reconocimientos médicos voluntarios iniciales y periódicos con el fin de verificar la adecuación del trabajador al puesto, y evitar los riesgos no solo para el trabajador sino también los que conviven en el hogar familiar".

${ }^{54}$ Ministerio de Trabajo y Economía Social, Estadística de accidentes de Trabajo (ATR). Informe metodológico estandarizado, marzo 2021 (visto el 26 de abril en http://mites.gob.es/eat/Informe_Metodologico_Estadarizado_ATR.pdf )

${ }^{55}$ En 2020, ese índice de EP es de 11,80 frente a, por ejemplo, 97,80 en actividades administrativas y de servicios. Y el número de partes de baja comunicados ese año es de 8, frente a los 971 en actividades
} 
La existencia de estos datos estadísticos sobre accidentes de trabajo y enfermedades profesionales en el trabajo doméstico, aun cuando solo reflejan lo que sucede en el empleo formal en el sector, debería servir para el diseño de políticas preventivas adecuadas, con objeto de eliminar los riesgos en el lugar de trabajo.

Desde luego, la supresión en este ámbito de todas las obligaciones mencionadas no queda paliada por el establecimiento, tanto en el art. 3.4 LPRL como en el art. 7.2 del RD 1620/2011, de una mera obligación genérica de seguridad del empleador que tiene unos contornos ciertamente indeterminados ${ }^{56}$, de los que difícilmente se pueden derivar concretas obligaciones preventivas salvo que vinieran previstas en la negociación colectiva, ni otra consecuencia que la dimisión del trabajador en caso de deficiencia grave, pues las sanciones administrativas no tienen en este caso cobertura legal.

Según la LPRL y el RD 1620/2011, el empleador debe cuidar de que el trabajo se realice en las debidas condiciones de seguridad e higiene, y para ello habrá de "adoptar medidas eficaces" (art. 7.2 RD) ${ }^{57}$. Las preguntas a las que una norma debería dar respuesta serían las de cuáles son las medidas preventivas en que se concretan las obligaciones de cuidado del empleador en la relación de trabajo doméstico, cómo se controla su cumplimiento y cómo se penaliza al infractor, en su caso.

A estas alturas, salvo que se reforme el art. 3 de la LPRL -bien sea para eliminar su exclusión, o bien para equipararles en su situación, al menos, a los colectivos a los que hace referencia en el aptado. 2 de ese precepto-, es necesaria una norma reglamentaria específica de protección de la salud de las trabajadoras domésticas que contemple las particularidades del sector, a la luz de las disposiciones del Convenio 189 OIT, una vez ratificado, y de la Recomendación 201 OIT. En definitiva, lo que resulta primordial para proteger la salud de las trabajadoras domésticas es la ratificación del Convenio 189 OIT $^{58}$, cumplidos casi 10 años desde su aprobación.

sanitarias y de servicios sociales. Visto el 27 de abril de 2021 en http://www.segsocial.es/wps/portal/wss/internet/EstadisticasPresupuestosEstudios/Estadisticas/EST231/2052

56 Se ha dicho que "carece de un contenido mínimo que oriente en su cumplimiento". ROMERAL HERNANDEZ, Josefa, "El impacto del Convenio 189 de la OIT en las condiciones de trabajo de los empleados de hogar", citado, p. 15.

57 El TSJ de Castilla y León, en sentencia de 9 de enero de 2017 (Rec. 2229/2016) señala que "para determinar si el equipo de trabajo era adecuado no son necesariamente aplicables las normas de seguridad y salud laboral de forma directa e íntegra, pero incluso si hubiéramos de aplicar las mismas como a cualquier otro trabajador por cuenta ajena en una relación laboral ordinaria, no aparece probado que se haya producido en este caso una vulneración de la normativa sobre escaleras de mano...". Y a continuación, sin embargo, pasa a evaluar el equipo de trabajo afectado, es decir, la escalera de mano de la que se cae la trabajadora, utilizando para ello la regulación prevista en el RD 1215/1997, de 18 de julio, por el que se establecen las disposiciones mínimas de seguridad y salud para la utilización por los trabajadores de los equipos de trabajo, norma de desarrollo de la LPRL. Esto podría ser muestra de la necesidad que existe, no sólo para los órganos judiciales, de contar con unas mínimas referencias normativas en torno a las obligaciones preventivas del empleador en la relación de trabajo doméstico.

${ }^{58}$ En este sentido, QUINTERO LIMA, Gema, "Salud laboral de las empleadas de hogar: una aproximación de urgencia", citado, p. 104, concluye que "a partir de las nuevas oportunidades que ofrecen el Convenio 189 (2011) y la Recomendación 201 (2011) de la Organización Internacional del Trabajo, en el marco del 


\section{Acoso y violencia en el trabajo doméstico y Convenio 190-OIT}

Dentro de la importante labor que ha realizado la OIT en la lucha contra la violencia en el ámbito del trabajo, con la aprobación de una serie de Convenios y Recomendaciones, destinados a la protección de los trabajadores en general, o bien de algún sector o grupo concreto, o alguna modalidad de violencia vinculada al trabajo ilegal como los relativos al trabajo forzoso, prohibición de trabajo infantil o discriminación en el empleo y en la ocupación $^{59}$, debe destacarse especialmente por su relevancia de la aprobación en 2019 del Convenio 190, junto a la Recomendación $206^{60}$. En efecto, la Conferencia General de la Organización Internacional del Trabajo en su $108^{a}$ reunión adoptó, el veintiuno de junio de 2019, el Convenio 190 sobre violencia y acoso en el mundo del trabajo, reconociendo el derecho de toda persona a un trabajo libre de violencia y acoso, incluidos la violencia y el acoso por razón de género, y reconociendo que la violencia y el acoso en el mundo del trabajo afectan a la salud psicológica, física y sexual de las personas, a su dignidad, y a su entorno familiar y social. Se trata del primer instrumento normativo de carácter internacional que trata sobre la violencia y acoso en el trabajo de forma global e integral y del que, además, se ha destacado su especial incidencia en el tratamiento de la violencia y acoso en el trabajo como materia indispensable e inseparable de la prevención y gestión de la seguridad y salud en el trabajo ${ }^{61}$.

En efecto, la adopción del Convenio 190 OIT es relevante por múltiples factores. En el sentido que aquí interesa lo es por dos elementos. Uno es la importante relación que establece entre las situaciones de violencia y acoso en el trabajo y la salud psicológica, física y sexual de las personas trabajadoras, y su voluntad de proteger en el mundo del trabajo frente a la violencia y el acoso en general, y frente a la violencia y acoso por razón de género en los términos definidos en el art. 1 del propio Convenio 190. En este sentido

Futuro del Trabajo y de las necesidades de un Trabajo Decente y Sostenible (Objetivos de Desarrollo Sostenible 1, 8, 11 de la Agenda 2030 de Naciones Unidas), sería preciso revisar el esquema de protección del Trabajo doméstico en general, pero en particular de la salud de las empleadas de hogar".

${ }^{59}$ TOMEI, Manuela, "Un mundo de trabajo libre de violencia y acoso: la apuesta del nuevo Convenio núm. 190 y Recomendación núm. 206 de la Organización Internacional del Trabajo", Noticias CIELO, ISSNe 2532-1226, No. 11, 2019, www.cielolaboral.com. Más in extenso YAGÜE BLANCO, Sergio, "El Convenio núm. 190 de la OIT sobre violencia y acoso: delimitación de su ámbito de aplicación ante la posible ratificación por España", Revista General de Derecho del Trabajo y de la Seguridad Social, 57, 2020, p. 501-502. También LOUSADA AROCHENA, José Fernando, "El Convenio 190 de la Organización Internacional del Trabajo sobre la violencia y el acoso en el trabajo", Revista de Derecho Social, núm. 88, 2019, p. 57 manifiesta la cercanía entre las situaciones de violencia y acoso en el trabajo con situaciones como la prohibición de trabajo forzoso, trabajo infantil y prohibición de discriminación.

${ }^{60}$ En abril de 2021, sólo 5 Estados han ratificado el Convenio 190 OIT: Argentina, Fiji, Namibia, Somalia, Uruguay, aunque su entrada en vigor se producirá el 25 de junio de 2021. España no ha ratificado aún este convenio.

${ }^{61}$ Pons CARMENA, Maria, "Aproximación a los nuevos conceptos sobre violencia y acoso en el trabajo a partir de la aprobación del Convenio OIT 190", Labos: Revista de derecho del trabajo y protección social vol. 1, 2020, p. 32. Sobre los diferentes modos de violencia laboral debe consultarse el trabajo de QUINTERO LIMA, Gema, "Las violencias del trabajo", en CORREA CARRASCO/QUINTERO LIMA (DIRS.), Violencia y acoso en el trabajo. Significado y alcance del Convenio $n^{\circ} 190$ OIT en el marco del trabajo decente (ODS 3,5,8 de la Agenda 2030), citado, pp. 307-317. 
partimos de la consideración de la violencia y acoso en el trabajo como acción pluriofensiva que no sólo tiene consecuencias en la igualdad y la dignidad de los trabajadores, sino que también supone una violación del derecho a la salud, en relación con los derechos a la vida y la integridad física y moral del art. 15 de la CE, y el deber de los poderes públicos de velar por la seguridad e higiene en el trabajo, del art. $40.2 \mathrm{CE}^{62}$. El segundo es el amplio ámbito subjetivo de aplicación definido en el art. 2 del Convenio, que permite su extensión a las trabajadoras domésticas, como veremos a continuación.

\section{El acoso y la violencia en el trabajo como riesgo para la salud en el Convenio 190- OIT}

El planteamiento que se va a realizar deja al margen el interesante debate sobre los tipos de conducta prohibidas e incluidas en los conceptos de violencia y acoso, así como la enorme variedad de conductas reprochables, punibles, censurables, inaceptables, cuya delimitación corresponderá a los legisladores nacionales según encomienda el art. 1.2 del Convenio $190^{63}$. Y esta decisión responde a que lo que aquí interesa está más próximo al resultado lesivo que la violencia y acoso en el trabajo provocan y que, como señalábamos, aparece ya en la propia definición de acoso y violencia en el trabajo del Convenio 190: la vinculación con la salud de las personas trabajadoras.

En concreto este precepto señala que a efectos del presente Convenio: "a) la expresión «violencia y acoso» en el mundo del trabajo designa un conjunto de comportamientos y prácticas inaceptables, o de amenazas de tales comportamientos y prácticas, ya sea que se manifiesten una sola vez o de manera repetida, que tengan por objeto, que causen o sean susceptibles de causar, un daño físico, psicológico, sexual o económico, e incluye la violencia y el acoso por razón de género", señalando a continuación que la definición de acoso y violencia por razón de género incorpora el importante matiz de que "van dirigidos contra las personas por razón de su sexo o género, o que afectan de manera desproporcionada a personas de un sexo o género determinado, e incluye el acoso sexual".

\footnotetext{
${ }^{62}$ En especial por cuestión de género, véase PÉREZ DEL RIO, M ${ }^{a}$ Teresa y BALLESTER PASTOR, ${ }^{a}$ Amparo, Mujer y salud laboral, Madrid, 1999; también PÉREZ DEL RIO, $\mathrm{M}^{\mathrm{a}}$ Teresa, La violencia de género en el ámbito laboral: el acoso sexual y el acoso sexista, Albacete, 2009, especialmente pp. 53-65. ${ }^{63}$ Sobre la cuestión puede verse ampliamente, YAGÜE BLANCO, Sergio, "El Convenio núm. 190 de la OIT sobre violencia y acoso: delimitación de su ámbito de aplicación ante la posible ratificación por España”, citado, p.520. En torno a la identificación de los aspectos más relevantes del impacto para nuestro sistema jurídico de la ratificación del Convenio 190 OIT (sobre prevención y erradicación de la violencia en el acoso en el trabajo) puede acudirse a MOLINA NAVARRETE, Cristóbal, "Impacto en España del convenio 190 OIT para la tutela efectiva frente a la violencia en el trabajo: obligados cambios legales y culturales", en CORREA CARRASCO/QUINTERO LIMA (DIRS.), Violencia y acoso en el trabajo. Significado y alcance del Convenio $n^{\circ} 190$ OIT en el marco del trabajo decente (ODS 3,5,8 de la Agenda 2030), citado, pp. 91-116. También a VELÁZQUEZ FERNÁNDEZ, Manuel, "Consecuencias de la aplicación del convenio 190 OIT sobre acoso y violencia en el trabajo en el Ordenamiento español”, en CORREA CARRASCO/QUINTERO LIMA (DIRS.), Violencia y acoso en el trabajo. Significado y alcance del Convenio $n^{\circ} 190$ OIT en el marco del trabajo decente (ODS 3,5,8 de la Agenda 2030), citado, pp. 281-305.
} 
Como puede apreciarse el resultado lesivo puede concretarse en efectivos daños físicos, psicológicos, sexuales y/o económicos, pero basta con que constituya un riesgo para la seguridad y salud, lo que manifiesta la lógica preventiva de la previsión normativa ${ }^{64}$. En este sentido se destaca que lo determinante va a ser el daño causado o la posibilidad de que se cause, lo que liga la violencia y acoso en el trabajo directamente con la protección de la seguridad y salud en el trabajo ${ }^{65}$; la intencionalidad lesiva deviene irrelevante, lo determinante es su vinculación causal con el entorno hostil y humillante al que se somete a la víctima ${ }^{66}$. Así, la importancia de que la violencia y el acoso en el trabajo sean considerados en el Convenio 190 como riesgos psicosociales supone, por un lado, que se robustece la prevalencia del elemento objetivo, el daño; y, en consecuencia, que se resta importancia a la necesidad de probar la intencionalidad lesiva o de causar daño, incluso una intención o finalidad discriminatoria ${ }^{67}$.

Obviamente esta vinculación entre la violencia y el acoso con la salud, que aparece claramente en el art. 1 del Convenio 190, se mantiene en las siguientes previsiones del Convenio 190, a las que vamos a referirnos, y que ponen de manifiesto la voluntad de reforzar la dimensión preventiva psicosocial ${ }^{68}$. En primer lugar, el art. 9 del Convenio 190, en el contexto del capítulo denominado "Protección y prevención" se refiere a las obligaciones que incumben a los Miembros de adoptar una legislación de prevención que concretamente tenga en cuenta la violencia y el acoso, así como los riesgos psicosociales asociados, en la gestión de la seguridad y salud en el trabajo, la identificación de los peligros y evaluación de los riesgos de violencia y acoso, con participación de los trabajadores y sus representantes, y adoptar medidas para prevenir y controlar dichos peligros y riesgos, y que proporcione a los trabajadores y otras personas concernidas, en forma accesible, según proceda, información y capacitación acerca de los peligros y riesgos de violencia y acoso identificados, y sobre las medidas de prevención y protección

\footnotetext{
${ }^{64}$ YAGÜE BLANCO, Sergio, "El Convenio núm. 190 de la OIT sobre violencia y acoso: delimitación de su ámbito de aplicación ante la posible ratificación por España”, citado, p. 523.

${ }^{65}$ PONS CARMENA, Maria, "Aproximación a los nuevos conceptos sobre violencia y acoso en el trabajo a partir de la aprobación del Convenio OIT 190", citado, p. 38.

${ }^{66}$ CORREA CARRASCO, Manuel, "El elemento teleológico (intencionalidad lesiva) en el concepto de violencia y acoso laboral contenido en el Convenio 190 OIT" en CORREA CARRASCO/QUINTERO LIMA (DIRS.), Violencia y acoso en el trabajo. Significado y alcance del Convenio $n^{\circ} 190$ OIT en el marco del trabajo decente (ODS 3,5,8 de la Agenda 2030), citado, p. 21

67 PONS CARMENA, Maria, "Aproximación a los nuevos conceptos sobre violencia y acoso en el trabajo a partir de la aprobación del Convenio OIT 190", citado, p.40. Como señala CORREA CARRASCO "suprimir o minusvalorar el elemento teleológico (intencionalidad lesiva) en la configuración conceptual de la violencia o acoso laboral supone, sin duda, una evidente ampliación del ámbito aplicativo sobre el que se proyecta el marco de protección jurídica diseñado, al incluir aquellas conductas que, aún careciendo de propósito alguno al respecto, han generado un resultado (ambiente o entorno de trabajo hostil, degradante u ofensivo) susceptible de dañar a los trabajadores afectados." CORREA CARRASCO, Manuel, "El elemento teleológico (intencionalidad lesiva) en el concepto de violencia y acoso laboral contenido en el Convenio 190 OIT", citado, p. 24.

${ }^{68}$ MOLINA NAVARRETE, Cristóbal, "Impacto en España del convenio 190 OIT para la tutela efectiva frente a la violencia en el trabajo: obligados cambios legales y culturales”, citado, p. 109 y ss.
} 
correspondientes. En este sentido la Recomendación 206 (párrafo 8) señala que: "En la evaluación de riesgos en el lugar de trabajo que se menciona en el artículo 9, c), del Convenio se deberían tener en cuenta los factores que aumentan las probabilidades de violencia y acoso, incluyendo los peligros y riesgos psicosociales. Debería prestarse especial atención a los peligros y riesgos que: a) se deriven de las condiciones y modalidades de trabajo, la organización del trabajo y de la gestión de los recursos humanos, según proceda; b) impliquen a terceros como clientes, proveedores de servicios, usuarios, pacientes y el público, y c) se deriven de la discriminación, el abuso de las relaciones de poder y las normas de género, culturales y sociales que fomentan la violencia y el acoso".

En segundo lugar, el art. 10 del Convenio 190, correspondiente al capítulo "Control de la aplicación y vías de recurso y reparación" merece una atención especial en la medida en que establece que los Miembros deben velar por que la inspección del trabajo y otras autoridades pertinentes, cuando proceda, estén facultadas para actuar en caso de violencia y acoso en el mundo del trabajo, incluyendo el dictado de órdenes que requieran la adopción de medidas de aplicación inmediata, o que impongan la interrupción de la actividad laboral en caso de peligro inminente para la vida, la salud o la seguridad de los trabajadores, a reserva de cualquier recurso judicial o administrativo que pueda prescribir la legislación ${ }^{69}$. Como se ha señalado anteriormente la labor de control de la Inspección de Trabajo en el trabajo doméstico en España se encuentra limitada, perdiéndose de este modo la adopción de medidas de control y de actuación en caso de violencia y acoso.

Pero además de legislar y controlar, en tercer lugar, imprescindible es la labor de "Orientación, formación y sensibilización”, para la cual el art. 11 del Convenio 190 se refiere a la necesidad de garantizar que la violencia y el acoso en el mundo del trabajo se aborden en las políticas nacionales pertinentes, como las relativas a la seguridad y salud en el trabajo, la igualdad y la no discriminación, y la migración. Quizás resulte definitiva las posibilidades de intervención de la negociación colectiva (art. 12) coadyuvante de la legislación nacional ${ }^{70}$.

Así pues, la ratificación del Convenio 190 OIT debe servir de estímulo para incluir la violencia y el acoso como riesgos psicosociales en la normativa en materia de prevención de riesgos, pero, además, como se ha señalado, puede y debe suponer un cambio de

\footnotetext{
${ }^{69}$ Para ello el párrafo 20 de la Recomendación 206 establece que: "Los inspectores de trabajo y los agentes de otras autoridades competentes, según proceda, deberán recibir formación específica sobre las cuestiones de género para poder detectar y tratar la violencia y el acoso en el mundo del trabajo, incluidos los peligros y riesgos psicosociales, la violencia y el acoso por razón de género y la discriminación ejercida contra determinados grupos de trabajo".

${ }^{70}$ QUINTERO LIMA, Gema, “Las violencias del trabajo”, en CORREA CARRASCO/QUINTERO LIMA (DIRS.), Violencia y acoso en el trabajo. Significado y alcance del Convenio $n^{\circ} 190$ OIT en el marco del trabajo decente (ODS 3,5,8 de la Agenda 2030), citado, p. 316.
} 
políticas y de culturas de gestión de la violencia y el acoso en el trabajo como riesgos psicosociales, de forma que mejore la calidad aplicativa, la eficacia y trasparencia ${ }^{71}$.

\section{El trabajo doméstico en el Convenio 190-OIT}

Una de las peculiaridades destacadas por la doctrina que se ha aproximado al estudio del Convenio 190 OIT es el de su amplio ámbito de aplicación personal. Es el art. 2 del Convenio 190 el que lo delimita en los siguientes términos: "1. El presente Convenio protege a los trabajadores y a otras personas en el mundo del trabajo, con inclusión de los trabajadores asalariados según se definen en la legislación y la práctica nacionales, así como a las personas que trabajan, cualquiera que sea su situación contractual, las personas en formación, incluidos los pasantes y los aprendices, los trabajadores despedidos, los voluntarios, las personas en busca de empleo y los postulantes a un empleo, y los individuos que ejercen la autoridad, las funciones o las responsabilidades de un empleador. 2. Este Convenio se aplica a todos los sectores, público o privado, de la economía tanto formal como informal, en zonas urbanas o rurales.". Imprescindible referirnos también al contenido del art. 3 del Convenio, que también supone una considerable ampliación de su ámbito de protección al definir que el Convenio se aplica a la violencia y el acoso en el mundo del trabajo que ocurren durante el trabajo, en relación con el trabajo o como resultado del mismo. Lo que incluye la violencia y el acoso que se manifiesten: a) en el lugar de trabajo, inclusive en los espacios públicos y privados cuando son un lugar de trabajo; b) en los lugares donde se paga al trabajador, donde éste toma su descanso o donde come, o en los que utiliza instalaciones sanitarias o de aseo y en los vestuarios; c) en los desplazamientos, viajes, eventos o actividades sociales o de formación relacionados con el trabajo; d) en el marco de las comunicaciones que estén relacionadas con el trabajo, incluidas las realizadas por medio de tecnologías de la información y de la comunicación; e) en el alojamiento proporcionado por el empleador -de especial interés para las trabajadoras domésticas internas-, yf) en los trayectos entre el domicilio y el lugar de trabajo.

La primera observación positiva que debe realizarse es la remisión a la noción de trabajo subordinado de cada una de las legislaciones y prácticas de los Miembros.

La segunda es que no incluye únicamente a los trabajadores asalariados típicos, sino también a las personas que trabajan al amparo de cualquier situación contractual, las personas en formación, pasantes y aprendices (es decir, las relaciones no formalmente laborales con finalidad formativa: becarios, prácticas formativas curriculares $o$ extracurriculares de los diferentes estudios de grado, postgrado o formación de algún tipo); a los trabajadores que han finalizado su prestación de servicios; a los que prestan servicios de tipo voluntario, sin percibir una retribución por el trabajo realizado en beneficio de organizaciones no gubernamentales o de forma no institucionalizada; a

\footnotetext{
${ }^{71}$ MOLINA NAVARRETE, Cristóbal, "Impacto en España del convenio 190 OIT para la tutela efectiva frente a la violencia en el trabajo: obligados cambios legales y culturales", citado, p. 110, 112-113.
} 
quienes buscan empleo, acceden a entrevistas o portales de empleo; y a quienes realizan funciones directivas, ejercen autoridad o responsabilidad propias de un empleados.

Pero, sobre todo, la tercera previsión que debe destacarse es la contenida en el apartado segundo del art. 2 respecto de los sectores en que se aplica: públicos o privados, urbanos o rurales, pero especialmente a la economía formal e informal.

Esta es, en nuestra opinión, una delimitación de un ámbito de aplicación que trata de no dejar sin protección a ningún sujeto que se encuentre en el ámbito de organización y dirección de un empleador, incluso aunque se trate de economía informal. En palabras de la propia OIT: "El término "economía informal» hace referencia al conjunto de actividades económicas desarrolladas por los trabajadores y las unidades económicas que, tanto en la legislación como en la práctica, están insuficientemente contempladas por sistemas formales o no lo están en absoluto. Las actividades de esas personas y empresas no están recogidas por la ley, lo que significa que se desempeñan al margen de ella; o no están contempladas en la práctica, es decir que, si bien estas personas operan dentro del ámbito de la ley, ésta no se aplica o no se cumple; o la propia ley no fomenta su cumplimiento por ser inadecuada, engorrosa o imponer costos excesivos"72. De manera que, conforme se ha interpretado, "el legislador internacional estaba incluyendo las actividades por cuenta propia, el trabajo en plataformas, el trabajo gig, freelancers, el trabajador autónomo económicamente dependiente, trabajadores que hacen pequeñas tareas (como la elaboración de bases de datos, lectura de reseñas de restaurantes y hoteles, cumplimentación de cuestionarios creación de sitios web, traducciones), pequeña artesanía, ventas online de particulares..."73. Esta inclusión de la economía informal deviene fundamental para la protección del trabajo doméstico que, como se ha señalado, tiene una alta incidencia de empleo informal ${ }^{74}$.

Pero, junto a esta delimitación amplia del concepto de trabajador, en este estudio sobre la protección frente a la violencia y el acoso en el trabajo doméstico, además, deben tomarse en consideración los artículos 5 y 6 del Convenio 190 OIT, no sólo en cuanto encomiendan prevenir y eliminar la violencia y el acoso a través de la eliminación de la discriminación en materia de empleo y ocupación, así como fomentar el trabajo decente y seguro, sino también en cuanto se refieren a trabajadoras y trabajadores pertenecientes a uno o a varios grupos vulnerables, o a grupos en situación de vulnerabilidad, en la medida en que están afectados de manera desproporcionada por la violencia y el acoso en

72 OIT, Resolución relativa al trabajo decente y la economía informal, 2002, https://www.ilo.org/public/spanish/standards/relm/ilc/ilc90/pdf/pr-25res.pdf

${ }^{73}$ RIBEIRO COSTA, Ana Cristina, "El contenido del convenio n ${ }^{\circ} 190$ de la organización Internacional del trabajo: definiciones y ámbito de Aplicación -“¿vino nuevo en odres viejos”?”, en CORREA CARRASCO/QUINTERO LIMA (DIRS.), Violencia y acoso en el trabajo. Significado y alcance del Convenio $n^{\circ} 190$ OIT en el marco del trabajo decente (ODS 3,5,8 de la Agenda 2030), DYKINSON, Madrid, 2021, pp. 39-40.

${ }^{74}$ OLARTE ENCABO, Sofía, "Los principios fundamentales del Convenio 190 OIT: un análisis desde la perspectiva de género. La novedosa inclusión del trabajo de servicio doméstico”, citado, p. 81. 
el mundo del trabajo. Debe precisarse aquí que la vulnerabilidad a la que se hace referencia se vincula a la transitoria, incorrecta e insuficiente protección ante la exposición a la violencia y e1 acoso $^{75}$.

$\mathrm{Al}$ respecto de los grupos vulnerables encontramos mayores indicaciones y concreciones en el párrafo 9 de la Recomendación 206 de la OIT, que se refiere de manera expresa a colectivos concretos, cuando encomienda a los miembros "adoptar medidas apropiadas para los sectores o las ocupaciones y las modalidades de trabajo más expuestos a la violencia y el acoso, tales como el trabajo nocturno, el trabajo que se realiza de forma aislada, el trabajo en el sector de la salud, la hostelería, los servicios sociales, los servicios de emergencia, el trabajo doméstico, el transporte, la educación y el ocio.".

Son varias las conclusiones que pueden extraerse.

Como puede apreciarse, la OIT se postula claramente por considerar el trabajo doméstico en sí mismo como sector especialmente expuesto a la violencia y el acoso. Previamente ya lo había señalado así el art. 5 del Convenio 189 OIT, que se refirió a la obligación de los Estados Miembros de "adoptar medidas para asegurar que los trabajadores domésticos gocen de una protección efectiva contra toda forma de abuso, acoso y violencia".

Pero, además, el Convenio 190 no olvida calificar a ciertos colectivos como especialmente vulnerables, cuyas características también son predicables de una parte importante de las trabajadoras domésticas.

En primer lugar, el Convenio reconoce que las mujeres son afectadas de manera desproporcionada por la violencia y el acoso en el trabajo, así como incluye la exigencia y adopción de medidas específicas para que ellas puedan beneficiarse de una protección efectiva $^{76}$.

Además, en segundo lugar, también existe una especial atención a las trabajadoras migrantes, como entendemos que ocurre al señalar el párrafo 10 de la Recomendación 206 que "Los Miembros deberían adoptar medidas legislativas o de otra índole para proteger a los trabajadores migrantes, y particularmente a las trabajadoras migrantes, contra la violencia y el acoso en el mundo del trabajo, con independencia de su estatus migratorio, en los países de origen, tránsito o destino, según proceda".

En tercer lugar, también debe adoptarse una especial protección frente a la violencia y el acoso en el trabajo en la economía informal (otra de las características del trabajo doméstico), y al mismo se refiere el párrafo 11 de la Recomendación 206, que señala que:

75 PONS CARMENA, María "Aproximación a los nuevos conceptos sobre violencia y acoso en el trabajo a partir de la aprobación del Convenio OIT 190", citado, p. 52.

76 TOMEI, Manuela, "Un mundo de trabajo libre de violencia y acoso: la apuesta del nuevo Convenio núm. 190 y Recomendación núm. 206 de la Organización Internacional del Trabajo”, Noticias CIELO, ISSNe 2532-1226, No. 11, 2019, www.cielolaboral.com, p. 2 
"Al facilitar la transición de la economía informal a la economía formal, los Miembros deberían proporcionar recursos y asistencia a los trabajadores y empleadores de la economía informal, y a sus asociaciones, para prevenir y abordar la violencia y el acoso en ésta".

Comprobamos de este modo que las trabajadoras domésticas deben ser consideradas colectivo vulnerable frente a la violencia y el acoso en el trabajo por una multitud de factores: por la especial preocupación del Convenio 190 y de la Recomendación 206 hacia la violencia y acoso por razón de género, es decir, contra las mujeres, lo que se corresponde también con el perfil mayoritario de trabajadoras domésticas; por las características del propio trabajo doméstico; por ser realizado por población migrante ${ }^{77}$, por mantenerse en la economía informal en un porcentaje excesivamente elevado.

De acuerdo con lo señalado, deviene inevitable la extensión de la protección frente a la violencia y el acoso no sólo al trabajo doméstico formal como grupo especialmente vulnerable, sino también y especialmente para aquellos trabajadores y trabajadoras domésticos que se sitúan en la economía informal ${ }^{78}$.

En definitiva, la especial vulnerabilidad de los trabajadores domésticos frente a la violencia y acoso en el trabajo deriva tanto de las condiciones de empleo (alto porcentaje de trabajo informal, especial lugar de trabajo en condiciones de invisibilidad y aislamiento $^{79}$, difícil control del tiempo de trabajo, especialmente en el caso del trabajo interno ${ }^{80}$ ), como del perfil de las trabajadoras domésticas (mujeres y migrantes); y esta especial vulnerabilidad debe ser tomada en consideración por los Estados Miembros que ratifiquen el Convenio 190 OIT y adecuen su normativa interna a este colectivo requerido de protección frente a la violencia y acoso en el trabajo. Ello exigiría tanto abordar las causas como los riesgos de violencia y acoso de género en el trabajo, y en este contexto la Recomendación (párrafo 5) encomienda una especial atención a los instrumentos de la OIT sobre igualdad y no discriminación -Convenio núm. 100 y la Recomendación núm. 90 sobre igualdad de remuneración, 1951, y el Convenio núm. 111 y la Recomendación núm. 111 sobre la discriminación (empleo y ocupación), 1958-; que deben sumarse a los instrumentos de la OIT sobre seguridad y salud en el trabajo (párrafo 6 de la Recomendación), tales como el Convenio núm. 155 sobre seguridad y salud de los

77 GÓMEZ RUFIÁN, Luis, “Características personales y condiciones jurídico-laborales del empleo doméstico en España...”, obra citada, p. 126.

${ }^{78}$ Sobre la cuestión vid supra el trabajo ya citado GÓMEZ RUFIÁN, Luis, "Características personales y condiciones jurídico-laborales del empleo doméstico en España...”, obra citada, pp. 122-123.

${ }^{79} \mathrm{Al}$ respecto se ha señalado que los trabajadores domésticos resultan invisibles al desarrollar su actividad laboral en la espera privada y al margen del posible control social o del Estado, lo que puede incidir en una mayor vulnerabilidad a las situaciones de violencia o acoso. En este sentido, OLARTE ENCABO, Sofía, "Los principios fundamentales del Convenio 190 OIT: un análisis desde la perspectiva de género. La novedosa inclusión del trabajo de servicio doméstico", citado, p. 67.

${ }^{80}$ Queremos destacar, en este sentido, que en el concepto de lugar de trabajo al que se refiere el art. 3 del Convenio 190 se incluye el alojamiento proporcionado por el empleador como ámbito de protección frente a la violencia y el acoso en el mundo del trabajo. 
trabajadores, de 1981, y el Convenio núm. 187 sobre el marco promocional para la seguridad y salud en el trabajo, de 2006.

\section{Una reflexión final: salud, violencia y trabajo decente}

No podemos finalizar estas reflexiones sin concluir recalcando la significativa influencia que la ratificación de estos convenios - el Convenio 189 y el Convenio 190- puede tener para la configuración de un marco normativo del trabajo doméstico libre de violencia y acoso y con una eficaz garantía de protección de su salud laboral, como elementos necesarios para la existencia de un trabajo doméstico decente en España, como hemos tratado de poner de manifiesto. Y en este sentido, como recuerda el Preámbulo del Convenio 190 OIT, la clave se encuentra, sin lugar a duda, en la prevención, recayendo esta responsabilidad en los Estados Miembros.

Desde esta perspectiva es posible mantener un enfoque de derechos humanos, de integración del concepto de trabajo decente, y de visualización de la incidencia desproporcionada de la violencia y el acoso en las mujeres y en las niñas, lo que conduce a una necesaria integración de la perspectiva de género también en materia de salud laboral, y especialmente en la lucha contra la violencia y el acoso en el trabajo ${ }^{81}$.

La violencia y el acoso en el mundo del trabajo afectan a la salud psicológica, física y sexual de las personas, a su dignidad, y a su entorno familiar y social, y en este contexto los Convenios OIT 189 y 190 contribuyen a reconocer el valor del trabajo doméstico para la sociedad, y a hacer hincapié en la dignidad y en la autonomía de los trabajadores domésticos, limando así las huellas de la cosificación histórica de estos trabajadores ${ }^{82}$. Efectivamente, estas normas internacionales de la OIT, que hemos de recordar han sido aprobadas por representantes de los gobiernos, de las organizaciones de trabajadores y de los empleadores, se configuran como un instrumento que puede servir de impulso para el desarrollo de verdaderas y eficaces políticas públicas en favor de las trabajadoras domésticas, especialmente en unos tiempos de crisis que han puesto de manifiesto tanto el transcendental papel del trabajo doméstico para los hogares familiares como la necesidad de cobertura adecuada de su protección social y de sus condiciones de trabajo, lo que incluye el desarrollo de su prestación de servicios en un entorno libre de peligros ${ }^{83}$.

81 En esta línea LOUSADA AROCHENA, José Fernando, "El Convenio 190 de la Organización Internacional del Trabajo sobre la violencia y el acoso en el trabajo", citado, p. 58.

82 OLARTE ENCABO, Sofía, "Los principios fundamentales del Convenio 190 OIT: un análisis desde la perspectiva de género. La novedosa inclusión del trabajo de servicio doméstico", citado, p. 72.

${ }^{83}$ La Federación Internacional de Trabajadores del Hogar (FITH) presentó el 18 de marzo de 2020 una declaración llamada "Manifiesto sobre la Protección de los Derechos de los Trabajadores y Trabajadoras del Hogar y la Lucha Contra la Pandemia del Coronavirus" (https://idwfed.org/es/relatos/global-fithdeclaracion-sobre-como-defender-los-derechos-de-las-trabajadoras-del-hogar-y-luchar-contra-

lapandemia-del-coronavirus), reclamando el derecho a un entorno de trabajo libre de peligros, lo que incluye "proveer equipo de protección, al igual que medidas y capacitación para usar dicho equipo 
En este contexto, entendemos que la ratificación de los Convenios mencionados y su incorporación al marco normativo español podría ser una oportunidad para la adopción de las siguientes medidas:

- la obligatoria adopción de medidas de prevención de riesgos laborales y de protección efectiva contra la violencia y el acoso en el trabajo para los y las trabajadoras domésticas, con especial incidencia de la perspectiva de género por la señalada feminización del sector;

- en este sentido, podría incrementarse la concesión de ayudas públicas para poner en marcha medidas de prevención de riesgos en los hogares en los que se contraten empleados domésticos; así como para la elaboración de protocolos de salud y seguridad que atiendan las especificidades del sector de trabajo doméstico remunerado, como se recomienda desde ONU-Mujeres ${ }^{84}$;

- el desarrollo de procedimientos de dialogo social, de carácter tripartito -gobierno, representaciones de empleadores y de trabajadoras domésticas-, y la necesidad de potenciar la libertad sindical y la negociación colectiva de las trabajadoras domésticas a través de sus organizaciones representativas ${ }^{85}$, incluso mediante la reforma de los criterios para medir dicha representatividad en un sector donde no existen órganos de representación unitaria, incorporando otros distintos ${ }^{86}$, como el de la afiliación ${ }^{87}$;

- la articulación de mecanismos de control e inspección en los domicilios de los empleadores, constituidos en lugares de trabajo, mediante el fortalecimiento de los ya existentes -a través de protocolos que garanticen su efectividad, pero también la privacidad y confidencialidad de las denuncias de las trabajadoras domésticas-, o el fomento de la realización de inspección sin ingreso en el domicilio, medidas también propuestas desde ONU-Mujeres ${ }^{88}$;

- el establecimiento de fórmulas para la presentación de quejas y de solución de conflictos en materia de violencia y acoso en el trabajo doméstico, así como para

adecuadamente. Los gobiernos deben asegurar que los y las trabajadores/as del hogar tengan el mismo acceso a medidas de protección, al igual que cualquier otro empleado/a y ciudadano/a."

${ }^{84}$ SALVADOR, Soledad y COSSANI Patricia, Trabajadoras remuneradas del hogar en América Latina y el Caribe frente a la crisis del COVID-19, [s.1.], ONU Mujeres, CEPAL, OIT [en línea]: http://repositorio.cepal.org/handle/11362/45724 [Consulta: 29/04/2020], citado, p. 9 de 19.

${ }^{85}$ LOUSADA AROCHENA, José Fernando, "El Convenio 190 de la Organización Internacional del Trabajo sobre la violencia y el acoso en el trabajo", citado, p.66.

${ }^{86}$ Sobre posibles reformas de la legislación laboral, en este u otros sentidos, con el objetivo de promover la negociación colectiva en el sector, vid. OIT, Protección eficaz de los trabajadores domésticos: guía para diseñar leyes laborales, Oficina Internacional del Trabajo, Ginebra, 2012, pp. 30-31.

87 En este sentido, BENAVENTE TORRES, Ma Inmaculada, "Dificultades para la negociación colectiva en el ámbito de la relación laboral especial del trabajo al servicio del hogar familiar”, citado, pp. 548.

${ }^{88}$ SALVADOR, Soledad y COSSANI Patricia, Trabajadoras remuneradas del hogar en América Latina y el Caribe frente a la crisis del COVID-19, [s.1.], ONU Mujeres, CEPAL, OIT [en línea]: http://repositorio.cepal.org/handle/11362/45724 [Consulta: 29/04/2020], p. 6 de 19. 
la reparación de las víctimas, no sólo con carácter indemnizatorio, sino también la instauración de instrumentos de ayuda y apoyo a quienes denuncien estas situaciones, tales como facilidades de recolocación laboral;

- por último, el desarrollo y apoyo a los diferentes recursos de formación para empleadas y empleadores puestos en marcha desde entidades públicas, asociaciones, y organizaciones sindicales y/o empresariales, así como la realización de campañas de sensibilización y de información general sobre los derechos laborales de las trabajadoras domésticas.

\section{Bibliografía}

BABIN, Angela, «Servicios personales y comunitarios: Empleados del hogar», en: Enciclopedia de salud y seguridad en el trabajo, Angela Babin (dir.), v.3, n.100, 2001, pp. 16-21. [en línea]. Consultado en: https://www.insst.es/tomo-iii

BENAVENTE TORRES, $M^{a}$ Inmaculada, "Dificultades para la negociación colectiva en el ámbito de la relación laboral especial del trabajo al servicio del hogar familiar", en Lex Social; Revista de Derechos Sociales, 11 (1), 2021.

BLACKETT, Adele, "Introductory Note to the Decent Work for Domestic Workers Convention, 2011 (NO. 189) and Recommendation (NO. 201)", en 53 ILM 250 (2014).

BLASCO MARTÍN, Elena, “Contribución especial: pequeño cuestionario para la acción sindical en el sector del trabajo doméstico", en Lex social: Revista de Derechos Sociales, vol. $9, \mathrm{n}^{\circ} 2,2019$.

BOFILL POCH, Silvia y VÉLIZ TORRESANO, Norma, Una violència oculta assetjament sexual en dones migrades treballadores de la llar i les cures, 2019, disponible en https://irla.cat/wp-content/uploads/2019/05/BECA-YARZA-unaviolencia-oculta-web.pdf

CARDENAL CARRO, Miguel, "A los 15 años de existencia de las relaciones laborales especiales. Un balance y una propuesta”, Aranzadi Social, núm. 9 y 10”, 2000.

CORDERO GORDILLO, Vanesa, La relación laboral especial del servicio del hogar familiar, RD 1620/2011, de 14 de noviembre, Tirant lo Blanch, Valencia, 2014.

CORREA CARRASCO, Manuel, "El elemento teleológico (intencionalidad lesiva) en el concepto de violencia y acoso laboral contenido en el Convenio 190 OIT" en CORREA CARRASCO/QUINTERO LIMA (DIRS.), Violencia y acoso en el trabajo. Significado $y$ alcance del Convenio $n^{\circ} 190$ OIT en el marco del trabajo decente (ODS 3,5,8 de la Agenda 2030), DYKINSON, Madrid, 2021 
CORREA CARRASCO, Manuel, "Los riesgos psicosociales en el trabajo doméstico y de cuidados", Lex Social: Revista De Derechos Sociales, Vol. 11(1), 2021.

CORREA CARRASCO/QUINTERO LIMA (DIRS.), Violencia y acoso en el trabajo. Significado y alcance del Convenio $n^{\circ} 190$ OIT en el marco del trabajo decente (ODS 3,5,8 de la Agenda 2030), DYKINSON, Madrid, 2021.

GARCIA TESTAL, Elena, "La necesidad de una protección por desempleo para los trabajadores domésticos en España”, en Revista de Derecho Social, núm. 79, 2017.

GARCIA TESTAL, Elena, "La extinción del contrato de trabajo de los trabajadores doméstico en España: un régimen jurídico injustificadamente diferenciado" Lex Social Revista de Derechos Sociales, Vol. 9, núm. 2/2019.

GARCIA TESTAL, Elena, "Trabajo doméstico y COVID-19" en Actualidad Jurídica Iberoamericana, núm. 12 bis, mayo 2020.

GÓMEZ RUFIÁN, Luis, “Características personales y condiciones jurídico-laborales del empleo doméstico en España: estudio a través de los microdatos de la encuesta de población activa”, en Lex Social: Revista De Derechos Sociales, 2019-9(2).

GRAU PINEDA, Carmen, "De sirvientas a trabajadoras: la necesaria ratificación del Convenio 189 OIT sobre trabajo decente para las trabajadoras y los trabajadores domésticos”, Lex Social Revista de Derechos Sociales, Vol. 9, núm. 2/2019.

HOBDEN, Claire, "Improving working conditions for domestic workers: organizing, coordinated action and bargaining", Issue Brief $n^{\circ} 2$, INWORK, International Labour Office, 2015.

LENZI, Olga, “Trabajo doméstico decente: ¿una combinación alcanzable en España?”, en El futuro del trabajo: cien años de la OIT, Ministerio de Trabajo, Migraciones y Seguridad Social, Madrid, 2019.

LOUSADA AROCHENA, José Fernando, "El Convenio 190 de la Organización Internacional del Trabajo sobre la violencia y el acoso en el trabajo", Revista de Derecho Social, núm. 88, 2019.

MOLINA NAVARRETE, Cristóbal, "Impacto en España del convenio 190 OIT para la tutela efectiva frente a la violencia en el trabajo: obligados cambios legales y culturales", en CORREA CARRASCO/QUINTERO LIMA (DIRS.), Violencia y acoso en el trabajo. Significado y alcance del Convenio $n^{\circ} 190$ OIT en el marco del trabajo decente (ODS 3,5,8 de la Agenda 2030), DYKINSON, Madrid, 2021.

NIETO ROJAS, Patricia, "Trabajo doméstico y derechos colectivos. Algunas reflexiones al hilo del RD 1620/2011 y del Convenio 189 OIT", en Lex social: Revista de Derechos Sociales, vol. 9, $\mathrm{n}^{\mathrm{o}}$ 2, 2019. 
OELZ, Martin, "El Convenio y la Recomendación de la OIT sobre las trabajadoras y los trabajadores domésticos. Una oportunidad para la justicia social”, Revista Internacional del Trabajo, (33-1) 2014.

OLARTE ENCABO, Sofía, "Los principios fundamentales del Convenio 190 OIT: un análisis desde la perspectiva de género. La novedosa inclusión del trabajo de servicio doméstico", en CORREA CARRASCO/QUINTERO LIMA (DIRS.), Violencia y acoso en el trabajo. Significado y alcance del Convenio $n^{\circ} 190$ OIT en el marco del trabajo decente (ODS 3,5,8 de la Agenda 2030), DYKINSON, Madrid, 2021.

PÉREZ DEL RIO, M ${ }^{\mathrm{a}}$ Teresa y BALLESTER PASTOR, $\mathrm{M}^{\mathrm{a}}$ Amparo, Mujer y salud laboral, Madrid, 1999

PÉREZ DEL RIO, Ma Teresa, La violencia de género en el ámbito laboral: el acoso sexual y el acoso sexista, Albacete, 2009,

POBLETE, Lorena, La producción de estándares laborales para el trabajo doméstico. La traducción del Convenio 189 en tres países del Sur: Argentina, Sudáfrica y Filipinas, Ed. CLACSO, Buenos Aires, 2015.

PONS CARMENA, María, “Aproximación a los nuevos conceptos sobre violencia y acoso en el trabajo a partir de la aprobación del Convenio OIT 190", Labos: Revista de derecho del trabajo y protección social, Vol. 1, n. ${ }^{\circ}$ 2, 2020.

QUESADA SEGURA, Rosa, "La dignificación del trabajo doméstico. El convenio n ${ }^{\circ} 189$, OIT, 2011", en Revista General de Derecho del Trabajo y de la Seguridad Social, (27), 2011.

QUINTERO LIMA, Gema, "Las violencias del trabajo", en CORREA CARRASCO/QUINTERO LIMA (DIRS.), Violencia y acoso en el trabajo. Significado $y$ alcance del Convenio $n^{\circ} 190$ OIT en el marco del trabajo decente (ODS 3,5,8 de la Agenda 2030), DYKINSON, Madrid, 2021.

QUINTERO LIMA, Gema, "Salud laboral de las empleadas de hogar: una aproximación de urgencia", en (BLÁZQUEZ AGUDO, Eva, (Dir.), Informe sobre la salud laboral desde la perspectiva de género, Universidad Carlos III de Madrid, 2017.

RAMOS QUINTANA, Margarita I., "Enfrentar la violencia y el acoso en el mundo del trabajo: la discusión normativa de la OIT", Revista del Ministerio de Trabajo, Migraciones y Seguridad Social, n. ${ }^{\circ}$ 138, 2018.

RIBEIRO COSTA, Ana Cristina, "El contenido del convenio n 190 de la organización Internacional del trabajo: definiciones y ámbito de Aplicación -“¿vino nuevo en odres viejos"?", en CORREA CARRASCO/QUINTERO LIMA (DIRS.), Violencia y acoso en el trabajo. Significado y alcance del Convenio $n^{\circ} 190$ OIT en el marco del trabajo decente (ODS 3,5,8 de la Agenda 2030), DYKINSON, Madrid, 2021. 
ROMERAL HERNANDEZ, Josefa, "El impacto del Convenio 189 de la OIT en las condiciones de trabajo de los empleados de hogar", en Revista Aranzadi Social, n ${ }^{\circ}$, 2013.

SALCEDO BELTRÁN, Carmen, "El trabajo doméstico en España: planteamientos y desafíos insoslayables frente a la "esclavitud moderna"”, Revista General de Derecho del Trabajo y de la Seguridad Social, núm. 55/2020.

SALVADOR, Soledad y COSSANI Patricia, Trabajadoras remuneradas del hogar en América Latina y el Caribe frente a la crisis del COVID-19, [s.1.], ONU Mujeres, CEPAL, OIT [en línea]: http://repositorio.cepal.org/handle/11362/45724 [Consulta: 29/04/2020].

SANZ SÁEZ, Concepción, "La discriminación en contra de las empleadas de hogar como forma de manifestación de las discriminaciones múltiples", en Revista de Derecho Social, núm. 83, 2018, p. 89-108.

SANZ SÁEZ, Concepción. "La exclusión de la prevención de riesgos laborales de la relación laboral especial del trabajo doméstico: análisis crítico de las posibles razones", Lan Harremanak, 44, 2020.

SANZ SÁEZ, Concepción (dir.) Reflexiones sobre el empleo doméstico. De dónde venimos, dónde nos encontramos y hacia dónde vamos, Servicio Central de Publicaciones del Gobierno Vasco, Victoria-Gasteiz, 2020.

SANZ SÁEZ, Concepción, "La precarización como realidad de mercado: la frontera entre el empleo doméstico y el trabajo de cuidados", en Lex Social, Vol. 11, n 1, 2021.

TOMEI, Manuela y BELSER, Patrick, "Nuevas normas de la OIT sobre trabajo decente para los trabajadores domésticos", Revista Internacional del Trabajo, vol. 130, (3-4), 2011.

TOMEI, Manuela, "Un mundo de trabajo libre de violencia y acoso: la apuesta del nuevo Convenio núm. 190 y Recomendación núm. 206 de la Organización Internacional del Trabajo", Noticias CIELO, ISSN-e 2532-1226, №. 11, 2019, www.cielolaboral.com

VELÁZQUEZ FERNÁNDEZ, Manuel, "Consecuencias de la aplicación del convenio 190 OIT sobre acoso y violencia en el trabajo en el Ordenamiento español”, en CORREA CARRASCO/QUINTERO LIMA (DIRS.), Violencia y acoso en el trabajo. Significado $y$ alcance del Convenio $n^{\circ} 190$ OIT en el marco del trabajo decente (ODS 3,5,8 de la Agenda 2030), DYKINSON, Madrid, 2021.

YAGÜE BLANCO, Sergio, "El Convenio núm. 190 de la OIT sobre violencia y acoso: delimitación de su ámbito de aplicación ante la posible ratificación por España", Revista General de Derecho del Trabajo y de la Seguridad Social, 57, 2020. 


\section{Anexo}

CCOO de Construcción y Servicios, Estudio para la detección de riesgos psicosociales en el Trabajo del Hogar AS2018-0012, Madrid, Ministerio de Trabajo, Migraciones y Seguridad Social, 2019. [en línea]. Consultado en: http://shorturl.at/dmEIZ

OIT, Resolución relativa al trabajo decente y la economía informal, 2002, https://www.ilo.org/public/spanish/standards/relm/ilc/ilc90/pdf/pr-25res.pdf

OIT, Guía práctica para la incorporación sistemática del empleo y el trabajo decente. Aplicación a nivel de país, Ginebra, 2008.

OIT, Trabajo decente para los trabajadores domésticos, Conferencia Internacional del Trabajo (99ª reunión), 2010.

OIT, Trabajo Decente para las trabajadoras y los trabajadores Domésticos. Convenio núm.189 y Recomendación núm. 201 en pocas palabras, Oficina Internacional del Trabajo, 2011.

OIT, Protección eficaz de los trabajadores domésticos: guía para diseñar leyes laborales, Oficina Internacional del Trabajo, Ginebra, 2012

OIT, Acabar con la violencia y el acoso contra las mujeres y los hombres en el mundo del trabajo, Informe V2, 2018.

OSALAN-Instituto Vasco de Seguridad y Salud laboral Guía básica de prevención de riesgos laborales para personas trabajadoras del hogar, Bilbao, 2019 (https://www.osalan.euskadi.eus/libro/guia-basica-de-prevencion-de-riesgos-laboralespara-personas-trabajadoras-del-hogar-2019/s94-contpub/es/) 